\title{
Experimental Deformation of Synthetic Magnetite-Bearing Calcite Sandstones: Effects on Remanence, Bulk Magnetic Properties, and Magnetic Anisotropy
}

\author{
MIKE JACKSON \\ Department of Geology and Geophysics, University of Minnesota, Minneapolis \\ GRAHAM BORRADAILE \\ Department of Geology, Lakehead University, Thunder Bay, Ontario, Canada \\ PETER HUdLESTON AND SUBIR BANERJEE \\ Department of Geology and Geophysics, University of Minnesota, Minneapolis
}

\begin{abstract}
We have quantified effects of experimental deformation on the magnetic properties of a set of synthetic "calcite sandstone" samples containing magnetite. The deformation was carried out in a microcomputer-controlled apparatus that adjusted the applied differential stress as needed to maintain a constant strain rate of $10^{-5} \mathrm{~s}^{-1}$. Most samples were deformed under dry conditions, but a few were deformed with a pore fluid present; the samples deformed under dry conditions required substantially higher differential stresses. Macroscopically ductile shortening strains of up to $25 \%$ produced the following irreversible changes in magnetic properties: (1) increased bulk coercivity, remanence coercivity, and mean anhysteretic remanekice susceptibility; (2) decreased mean low-field susceptibility; (3) decreases in the component of remanence parallel to shortening; (4) smaller decreases for most samples in the component nortitial to shortening, resulting in a net "rotation" of the remanence away from the shortening axis; (5) larger decreases in the normal component in a few samples, resulting in a net "rotation" of the remanence towards the shortening axis; (6) increased magnetic anisotropy; and (7) increased "deformation" of initial magnetic ellipsoids. A comparison of data for samples deformed under dry and wet conditions (higher and lower differential stresses, respectively) indicates that remanence reorientation and susceptibility anisotropy are controlled primarily by bulk strain (i.e., rotation and displacement of particles), whereas coercivity and anhysteretic anisotropy are controlled dominantly by microstrain or intragranular stress.
\end{abstract}

\section{INTRODUCTION}

Stress and strain may significantly affect rock magnetic properties in a variety of ways. Differential stresses or even hydrostatic stresses can directly influence the behavior of magnetostrictive ferromagnetic mineral grains, especially the titanomagnetites [e.g., Kean et al., 1976; Carmichael, 1968a, b; Revol et al., 1977; Kapicka, 1988]. Strain may reorient ferromagnetic grains (without deforming them) by a variety of mechanisms, including ductile deformation of the matrix, particulate flow, and dissolution processes acting on the matrix material (see Borradaile [1988, 1991] for a recent review). In addition, ferromagnetic particles may themselves experience some internal deformation, if sufficiently large differential stresses are transmitted by the surrounding particles [Muller and Siemes, 1972; Hennig-Michaeli and Siemes, 1975]. The results of these diverse processes may find expression in a variety of magnetic properties, the most important of which are anisotropy, changes in remanence orientation and intensity, and changes in bulk magnetic properties such as coercivity and susceptibility.

The relationship between magnetic properties and finite strain has most often been investigated empirically, that is, by measuring the magnetic anisotropy or natural remanence and the strain ellipsoid in naturally deformed rocks, and searching for systematic rela-

\section{Copyright 1993 by the American Geophysical Union.}

Paper number 92JB01028.

$0148-0227 / 93 / 92 \mathrm{JB}-01846 \$ 05.00$ tionships [Graham, 1967; Singh et al, 1975; Kneen, 1976; Wood et al, 1976; Kligfield et al, 1977, 1981, 1982, 1983; Rathore, 1979; Rathore and Henry, 1982; Cogné and Perroud, 1985, 1987, 1988; Hirt et al, 1986, 1988; Lowrie et al, 1986; Ruf et al, 1988]. A fundamental limitation of the empirical approach is that many of the important variables are uncontrolled, including magnetic mineralogy and grain size [Borradaile, 1987; Rochette, 1987] (see also Henry [1983] and Henry and Daly [1983]), primary magnetic fabric [Hrouda, 1992] and primary remanence characteristics, as well as strain rate and stress magnitudes and orientations. A useful alternative approach is experimental rather than empirical [Kodama and Cox, 1978; Owens and Rutter, 1978; Borradaile and Alford, 1987, 1988; Borradaile and Mothersill, 1989], in which samples of controlled, uniform composition, and known initial magnetic states, are deformed under precise laboratory conditions.

In this paper we present the results of an experimental investigation into the simultaneous effects of deformation on magnetic remanence, bulk magnetic properties, and magnetic anisotropy in a set of synthetic, magnetite-bearing samples. This study expands on the previous investigation of Borradaile and Alford [1987] by examining remanence and bulk properties as well as anisotropy, and by including measurements of both anisotropy of magnetic susceptibility (AMS) and anisotropy of anhysteretic remanence (AAR; also referred to as anisotropy of anhysteretic susceptibility (AAS) [McCabe et al., 1985].

Stress effects. Even in the absence of permanent strain, externally applied stresses influence the direction and intensity of remanence [e.g., Martin and Noel, 1988; Lanham and Fuller, 1988], as well as 
susceptibility anisotropy [€.g., Kean et al., 1976; Kapicka, 1988], because of the phenomenon of magnetostriction. These stress effects may be reversible (witn removal of the applied stress) or irreversible. Additionally, internal stresses (or microstresses) associated with dislocations, compositional variations, etc., have strong effects on basic magnetic properties [Hodych, 1982, 1986; Soffel, 1966; Xu and Merrill, 1989, 1990; Xu and Dunlop, 1990; Worm et al., 1991].

In magnetostrictive materials such as magnetite [Hodych, 1982, 1986; Worm et al., 1991] and especially Ti-rich titanomagnetite [Appel, 1987; Moskowitz et al., 1988], differential stresses of the order of 50 to $100 \mathrm{MPa}(0.5$ to $1 \mathrm{kbar}$ ) are sufficient to cause irreversible remanence rotation and domain wall translation [Carmichael, 1968b] as well as nucleation of new domains [Boyd et al., 1984; Halgedahl, 1987]. There is clear experimental evidence for significant stress effects on the remanence of (titano)magnetites: most frequently relatively low stresses result in partial demagnetization of preexisting remanence, and higher stresses produce new components of remanent magnetization [Kern, 1961a, b; Nagata and Carleton, 1968; Kinoshita, 1968; Ohnaka, 1969; Nagata, 1970; Revol et al., 1977; Martin et al., 1978; Martin and Noel, 1988; Lanham and Fuller, 1988; Borradaile and Mothersill, 1989]. In addition, several studies have presented empirical evidence for stress remagnetization in nature [Graham et al., 1957; Hudson et al., 1989].

Stress-induced changes in susceptibility, especially the development of AMS, have been described by a number of researchers [e.g., Kern, 1961a; Kean et al., 1976; Kapicka, 1988]. These investigations in the reversible, elastic regime have been motivated in part by the importance of devising methods for earthquake prediction; there is some empirical evidence that rocks may act as "magnetic stress transducers" producing transient local magnetic field anomalies as stresses change before a seismic event [e.g., Smith and Johnston, 1976]. Experimental results indicate that susceptibility changes produced by stresses up to $50 \mathrm{MPa}$ are essentially reversible [Kapicka, 1988], in contrast to the largely irreversible effects on remanence.

It is now also widely appreciated that internal stress in magnetites has a strong influence on bulk magnetic properties such as coercivity and intrinsic susceptibility [Hodych, 1982, 1986; $X u$ and Merrill, 1989; Worm et al., 1991]. Empirical evidence for this is provided by the significant differences exhibited by crushed and sieved magnetites on the one hand, and hydrothermally or chemically precipitated magnetites of the same size on the other [Heider et al., 1987]. Invariably, crushed grains are magnetically "harder" than precipitated grains: they have higher coercivities, higher saturation remanence, and lower susceptibility. These differences are due to the presence of larger energy barriers to domain wall movement, which are associated with high residual stresses. The stresses are presumably related to lattice defects such as dislocation pileups.

However, few experimental data exist on how these magnetic properties change (irreversibly) as a function of applied stress. Carmichael [1968b] reported that repeated application of $50 \mathrm{MPa}$ uniaxial stress had no effect on the bulk coercivity and saturation remanence (acquired after unloading) in magnetite monocrystals. In contrast, Baleyev and Absalyamov [1983] found significant increases in both dislocation density and coercivity after uniaxially stressing magnetite monocrystals to $50 \mathrm{MPa}$, and also after hydrostatically stressing magnetite powders.

Strain effects. Experimental studies have shown that magnetite single crystals or massive ores deform at moderately low temperatures by twin- and translation-gliding mechanisms, under a differential stress of a few hundred megapascals [Muller and Siemes, 1972; Hennig-Michaeli and Siemes, 1975]. Brittle deformation (fracturing) of magnetites may also be expected to occur under some conditions of natural deformation and has been reported by Hudson et al. [1989] in remagnetized sandstones from the Wyoming-Idaho thrust belt. Clearly, either brittle or crystalplastic deformation can be expected to have significant effects on magnetic properties. However, in general, strain is thought to alter the magnetic properties of a rock principally by reorientation of the magnetic grains, rather than by deforming them.

The mechanism by which magnetic particles reorient during deformation is critically important in modeling the effects of strain upon magnetic anisotropy and upon remanence [Owens, 1974; Hrouda, 1976, 1987; Facer, 1983; Cogné and Gapais, 1986; Cogné et al., 1986; Henry and Hrouda, 1989; van der Pluijm, 1987; Kodama, 1988]. Three simple microscopic models are often discussed: the particles may behave as rigid spheres or ellipsoids rotating in a viscous fluid [Jeffery, 1922], as undeformable linear/planar elements [March, 1932], or as deformable "passive markers" with no mechanical contrast between the magnetic particles and the nonmagnetic matrix. Which of these idealized models (if any) apply in any particular situation is not obvious. For further discussion the reader is referred to Owens [1974], Cogné and Perroud [1985, 1987], Lowrie et al. [1986], van der Pluijm [1987], Kodama [1988], Hrouda [1987], Rochette [1988], and Borradaile [1988].

Empirical evidence for modification of a natural remanence by strain has been presented by Kligfield et al. [1983], Cogné and Perroud [1985, 1987], and Vetter et al. [1989]; experimental studies have been conducted by Ozima [1980], Morash and Bonhommet [1981], and Borradaile and Mothersill [1989]. In some cases [e.g., Borradaile and Mothersill, 1989], remanence appears to rotate faster than a "nonmaterial line", i.e., a linear marker with no mechanical competence contrast; in others [e.g., Cogné and Perroud, $1985,1987]$ a nonmaterial line model appears to be reasonably accurate; in still others [e.g., Lowrie et al., 1986] remanence rotates more slowly than a nonmaterial line, so that "destraining" the final remanence vectors (multiplying them by the inverse strain tensor) overcorrects the remanence directions. More recent work has shown that for multicomponent remanence, deformation may preferentially remove one component on the basis of coercivity, so that the total remanence vector may rotate either toward or away from the shortening direction, behavior which is qualitatively different from the rotation of a non-material line [Borradaile and Mothersill, 1991; Borradaile 1992]. Susceptibility ellipsoids always appear to "deform" more slowly than passive markers; a relationship of the form $\ln \left(k_{\max } / k_{\min }\right) \sim a \ln (X / Z)$ has been found in a number of cases, with $a$ ranging from about 0.3 downwards [Singh et al., 1975; Kneen, 1976; Wood et al., 1976; Kligfield et al., 1977, 1981, 1982, 1983; Rathore, 1979; Rathore and Henry, 1982; Cogné and Perroud, 1985, 1987, 1988; Hirt et al., 1986, 1988; Lowrie et al., 1986; Ruf et al., 1988].

\section{EXPERIMENTAL METHODS}

\section{Sample Preparation}

Procedures for sample preparation in this study closely follow those described by Borradaile and Alford [1987]. The relatively nonmagnetic matrix material consists of Portland cement ( $30 \%$ by weight) and calcite (70\%), the latter obtained by crushing large individual crystals, and sieving to a size range of 150 to $175 \mu \mathrm{m}$. 
We have used finer-grained magnetite in this study (mean diameter $40 \mu \mathrm{m})$ than that used by Borradaile and Alford $(200-300 \mu \mathrm{m})$, in order to better represent the carriers of natural remanence in most rocks. Scanning electron microscope (SEM) observations show that these commercially obtained crushed and seived magnetite grains are predominantly subequant, although a range of shapes is present. Preliminary tests showed that the cement contains a slight ferrimagnetic contamination, but it contributes less than $5 \%$ to the anhysteretic remanent magnetization (ARM) and susceptibility of the final samples.

The magnetite was dispersed in a slurry of cement using a household electric blender; additional cement and the calcite sand were then added and stirred by hand. This method was quite effective at dispersing the magnetite; however some heterogeneity in magnetite concentration is inevitable. The mixture was poured into a flat mold and probed repeatedly with a nonmagnetic wire to remove as many air bubbles as possible. After the cement had cured for approximately two weeks, $1.25 \mathrm{~cm}$ diameter cores were drilled; the cores were then cut to a length of $2.5 \mathrm{~cm}$ (to provide the optimum shape for experimental deformation). The ends were milled to precise right angles, and initial dimensions were measured to within $\pm 0.03 \mathrm{~mm}$.

\section{Initial Magnetic Characterization}

Low-field magnetic susceptibility tensors $\left[\mathrm{k}_{1}\right]$ were measured using an automated apparatus constructed by J. Marvin. A microcomputer-controlled sample handler rotates a specimen through three orthogonal planes, and susceptibility measurements are made at $1.8^{\circ}$ intervals. The susceptibility tensor is computed by least squares from the resulting 600 directional measurements. Very high precision results from the large number of measurements; in almost all cases principal axis orientations are reproducible to within about $2^{\circ}$, and axial ratios and mean susceptibilities are reproducible to within about $1 \%$.

Because the specimen shapes are far from the optimal length/diameter $(l / d)$ ratio of 0.86 for magnetic measurements [Noltimier, 1971], all measured initial susceptibility ellipsoids were prolate, with the long axes parallel to the specimen axes. For this reason we have applied a shape correction to the susceptibility tensors, derived by measuring the AMS of specimens of isotropic paramagnetic $\mathrm{Mn}_{2} \mathrm{O}_{3}$ powder packed into containers with precisely the same cylindrical shape as the calcite sandstone cores. This isotropic standard also yielded a prolate ellipsoid, with roughly the same degree of anisotropy as most of the synthetic rocks. The correction factor we have applied is the inverse of the $\mathrm{Mn}_{2} \mathrm{O}_{3}$ tensor; by definition this produces an isotropic corrected tensor for the $\mathrm{Mn}_{2} \mathrm{O}_{3}$, and in practice it results in weakly anisotropic tensors for the individual specimens, and nearly random principal axis orientations (Figure 1). We note that this correction procedure was directly verified for one specimen (specimen 11) when it was accidentally broken; one of the resulting pieces was very close to the optimum $l / d$ ratio of 0.86 , and its measured tensor was essentially identical to the corrected tensor for the whole long core.

Following the AMS measurements, ARM tensors $\left[k_{a}\right]$ were also measured for each sample. Remanences were imparted in an alternating field (af) of $95 \mathrm{mT}$ with a superimposed parallel steady field of $150 \mu \mathrm{T}$; measurements were made on a three-axis 2-G superconducting magnetometer. Because this instrument is quite insensitive to sample shape, no correction was necessary for the ARM tensors (this was directly verified for specimen 11). Tensors and mean $k_{a}$ values were determined following the procedure of McCabe et al. [1985] (adapted from Girdler [1961]), involving
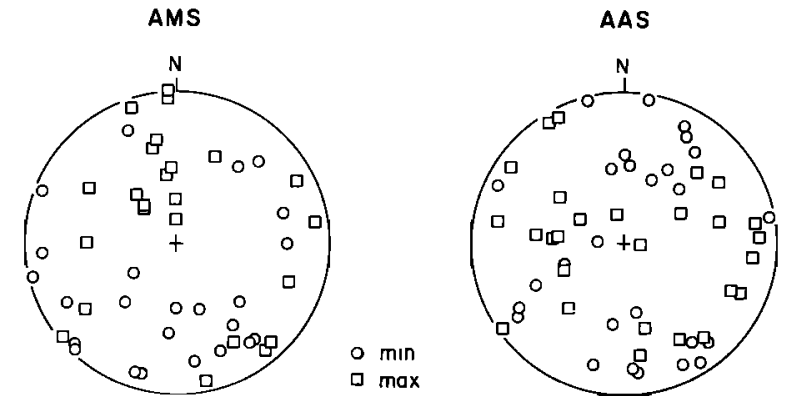

a)

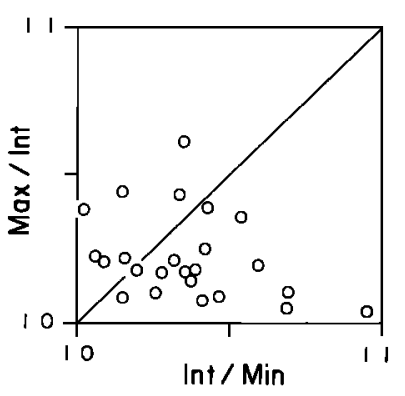

b)

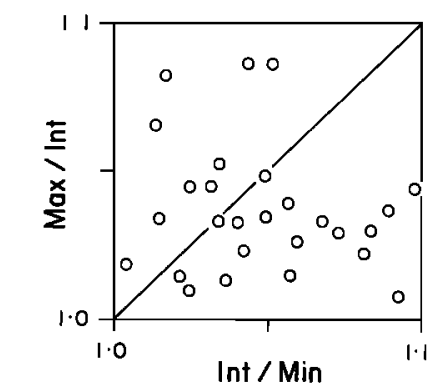

d)

Fig. 1. Equal-area and Flinn-type plots illustrating orientations and shapes of initial anisotropy of magnetic susceptibility (AMS) and anisotropy of anhysteretic susceptibility (AAS) ellipsoids; note weak anisotropies and essentially random orientations.

measurements in nine different directions and derivation of the ellipsoid by least squares. As was the case for the corrected susceptibility ellipsoids, the initial ARM ellipsoids are rather weakly anisotropic and not consistently oriented (Figure 1).

The final step in the ARM anisotropy algorithm is to impart and measure an $\mathrm{ARM}$ at a $45^{\circ}$ angle to the core axis (with a declination of $270^{\circ}$ ). Due to the weak initial ARM anisotropy and to careful orientation during magnetization, the actual measured ARM was in all cases within $2^{\circ}$ of this orientation. For almost all of the cores, this constituted the predeformational remanence. However, two sets of specimens started with somewhat different remanence states. In one set of samples, the inclined ARM was demagnetized, and an ARM was given parallel to the axis of the core. Another set of four specimens was subjected to high-field hysteresis measurements in a vibrating sample magnetometer (VSM); due to the geometry of the specimens and the VSM, these measurements were made at right angles to the core axis (azimuth $270^{\circ}$, plunge $0^{\circ}$ in the sample coordinate system). These were then given an ARM in the same orientation as the other samples $\left(270^{\circ}, 45^{\circ}\right)$.

\section{Deformation}

Methodology for the deformation runs closely followed that of Borradaile and Alford [1987]. The samples were jacketed in Teflon tubing, and then shortened parallel to their cylindrical axes in a microcomputer-controlled triaxial deformation apparatus [Donath, 1970], at room temperature under a confining pressure of $150 \mathrm{MPa}$. A constant strain rate was maintained by automatic adjustment of the applied differential stress; stress-strain histories were recorded by the microcomputer, which applied corrections for apparatus distortion and change of specimen shape. For most samples the strain rate was $1 \times 10^{-5} \mathrm{~s}^{-1}$, but in a few cases this was reduced to $5 \times 10^{-6} \mathrm{~s}^{-1}$ in order to observe the effects of deformation at lower differential stresses. For the same reason, one set of 
samples (samples 23-28, Table 1) was deformed with a pore fluid present at a pressure of $100 \mathrm{MPa}$; the rest of the cores were deformed under dry conditions. Shortening strains up to $25 \%$ $\left(e_{3}=\left(l / l_{0}-1\right) \geq-0.25\right)$ were attained without macroscopic brittle failure. Finally, several samples were subjected to the same hydrostatic confining pressure but no differential stress.

TABLE 1. Peak Applied Stress and Strain

\begin{tabular}{lrcc}
\hline Sample & $\begin{array}{c}\text { Differential } \\
\text { Stress, } \\
\text { MPa }\end{array}$ & $\begin{array}{c}\text { Shortening, } \\
\text { percent }\end{array}$ & $Z=1+e_{3}$ \\
\hline & & & \\
2 & & 18.96 & \\
3 & 172.0 & 15.27 & 0.81 \\
4 & 144.0 & 15.00 & 0.85 \\
5 & 122.0 & 12.47 & 0.85 \\
6 & 95.0 & 20.40 & 0.88 \\
7 & 151.0 & 15.00 & 0.80 \\
8 & 38.0 & 14.70 & 0.85 \\
9 & 48.0 & 11.60 & 0.85 \\
10 & 89.0 & 26.50 & 0.88 \\
11 & 170.0 & 0.00 & 0.74 \\
12 & 0.0 & 10.34 & 1.00 \\
13 & 82.0 & 9.80 & 0.90 \\
14 & 48.0 & 7.20 & 0.90 \\
15 & 38.0 & 0.00 & 0.93 \\
16 & 0.0 & 11.80 & 1.00 \\
17 & 90.5 & 14.50 & 0.88 \\
18 & 140.7 & 19.96 & 0.86 \\
19 & 199.2 & 17.24 & 0.80 \\
20 & 166.3 & 14.00 & 0.83 \\
21 & 103.9 & 21.90 & 0.86 \\
22 & 166.8 & 14.90 & 0.78 \\
23 & 129.5 & 23.40 & 0.85 \\
24 & 91.0 & 3.90 & 0.77 \\
25 & 24.0 & 15.80 & 0.96 \\
26 & 63.5 & 11.80 & 0.84 \\
27 & 46.0 & 20.10 & 0.88 \\
28 & 55.0 & 8.20 & 0.80 \\
& 32.7 & & 0.92 \\
\hline & & & \\
\hline & & &
\end{tabular}

\section{Postdeformational Magnetic Characterization}

Magnetic measurements for the deformed samples were performed in the following sequence: measurement of $\left[\mathrm{k}_{1}\right]$; measurement and stepwise AF demagnetization of the postdeformational remanence; a second measurement of AMS (for some samples); measurement of $\left[\mathrm{k}_{\mathrm{a}}\right]$; and finally, measurement of highfield hysteresis properties. The second set of AMS measurements was intended to evaluate the possible presence of metastable domain anisotropies, which Park et al. [1988] have shown to be removable by AF demagnetization.

\section{RESULTS}

\section{Nature of Deformation}

A typical stress-strain curve for a dry sample (Figure $2 a$ ) shows that continually increasing differential stresses are required to maintain a constant strain rate; there is no clear yield point. The presence of a pore fluid substantially alters the mechanical behavior, with a well-defined yield point and a relatively low flow stress (Figure 2a). A summary plot of maximum applied differential stress and finite strain for the individual samples shows a clear, approximately linear relationship (Figure $2 b$ and Table 1). Samples deformed under wet conditions also define a generally linear trend in Figure $2 b$, but with a substantially lower slope (i.e., they deform at lower differential stresses, as expected [Rutter, 1974]). The quasilinear trend defined by the dry deformation experiments exhibits small discontinuities at approximately $10 \%$ and $15 \%$ strain; slightly higher strains in each case appear to require significantly higher differential stresses. The $15 \%$ discontinuity corresponds to the final closure of initial porosity; measurements of external dimensions show continuous volume loss up to $15 \%$ shortening, and constant-volume strain thereafter.

Stress-relaxation tests [e.g., Rutter et al., 1978] show a weak dependence of differential stress upon strain rate (Figure $2 c$ ), with $e$ proportional to $\sigma^{n}$, and $n \sim 14$. There is perhaps some indication of a greater sensitivity for strain rates below about $10^{-7} \mathrm{~s}^{-1}$, but this is less clear than the change observed by Borradaile and Alford [1987] for quartz sand samples. The sample deformed under wet conditions was slightly weaker at all strain rates (Figure $2 c$ ).

Several mechanisms are probably responsible for the overall strain. Microcracking at cement-grain boundaries and deformation of the cement gel enables grain rotation and disordered grain-scale translation, or "particulate flow" [Borradaile and Tarling, 1981, 1984; Borradaile, 1981, 1988]. The calcite framework grains also deform by e-twinning, especially at higher strains. It appears that particulate flow, accompanied by closure of pore space, accounts for most of the strain in the earlier stages of deformation (Figure 3). As shortening proceeds, the framework grains come into increasing mutual contact, and both systematic rotation and internal deformation of these grains is more efficient thereafter (Figure 3). The transition between these dominant modes of deformation may account for the apparent stress-strain discontinuity at about $10 \%$ strain (Figure $2 b$ ); this appears to represent the point where porosity is sufficiently diminished that a framework of clasts begins to support the applied load, although volume loss continues to $15 \%$ shortening.

\section{Changes in Rock Magnetic Properties with Deformation}

Both mean susceptibility and mean $k_{a}$ change significantly with deformation (Figure 4, Table 2). Bulk susceptibility is largely unaffected in samples with less than about $10 \%$ strain; in more strongly deformed samples it is diminished by as much as 10 or $15 \%$. However, for the most strongly deformed samples (with shortening strains near $25 \%$ ) the bulk susceptibility after deformation is nearly the same as the initial value. Mean $k_{a}$ values show a significant increase in almost all samples; even those that only experienced hydrostatic stress have values $10 \%$ higher than the original measurements. Otherwise, the ARM data fall on the plot in a rough mirror image of the susceptibility data: mean ARMs are nearly constant (at about 1.1 times initial values) up to about $10 \%$ strain, and they are significantly increased in more strongly deformed specimens, in some cases by $25 \%$. There is significant scatter in the data, both as a function of strain and as a function of peak differential applied stress (Figure 4).

The ratio of $k / A R M$ is often taken as a measure of relative or effective ferromagnetic grain size [Banerjee et al., 1981; King et $a l ., 1982]$. Figure 4 also shows how this ratio is changed by the deformation. Even in the most weakly deformed or undeformed samples (with one exception), the relative grain size indicated by $(k / \mathrm{ARM})_{d} /(k / \mathrm{ARM})_{o}$ (where the subscripts $d$ and $o$ refer to the deformed and original states, respectively) is reduced to about $90 \%$. For samples shortened by more than about $10 \%$, this ratio is sharply decreased, by an amount that is roughly proportional to the strain magnitude. 

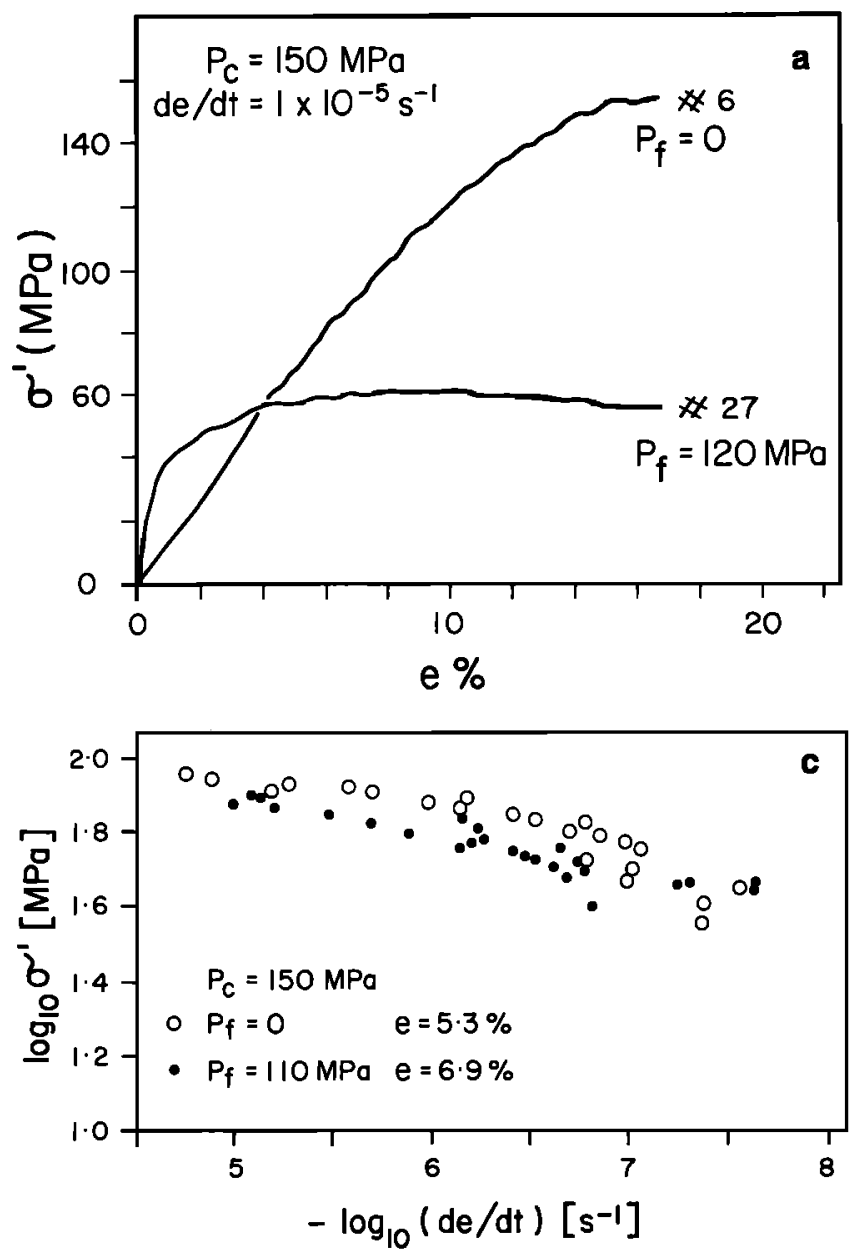

It is important to point out that in this context, the changes in the ratio $k / A R M$ do not necessarily indicate changes in the actual size of the magnetite grains. This ratio is essentially an indicator of magnetic "hardness." In natural rocks and sediments with a range of grain sizes, hardness is in general inversely related to grain size; hence the success of its application to granulometry. In the samples of this study, grain size reduction by fracturing (as in Figure 3) is quite rare, and in general the magnetic hardness is increased at constant grain size (e.g., by accumulation of internal stress or by mechanical deformation). The microscopic processes responsible for the enhanced magnetic hardness of the deformed samples will be the subject of future investigation.

Hysteresis properties were measured for four samples prior to deformation, and for all samples after deformation (Table 2). The samples for which these properties were initially measured all yielded essentially identical results: the ratio of saturation remanence to saturation magnetization $\left(J_{r s} / J_{s}\right)$ was $0.055( \pm 0.002)$, and the bulk coercivity $\left(H_{c}\right)$ was $5.0 \pm 0.1 \mathrm{mT}$. Comparison with published data summarized by Dunlop and Argyle [1990] shows that these values are typical for crushed magnetites of $40 \mu \mathrm{m}$ diameter. Figure 5 shows the variation in hysteresis properties measured after deformation. The ratio $J_{r s} / J_{s}$ and the bulk coercivity $H_{c}$ both increased significantly for samples shortened by $10 \%$ or more. The increases were smaller for samples deformed with a pore fluid present than they were for samples shortened by the same amount under dry conditions at higher differential stresses (Tables 1 and 2). Thus the hysteresis properties vary more systematically with peak applied stress than they do with bulk strain (Figure 5).

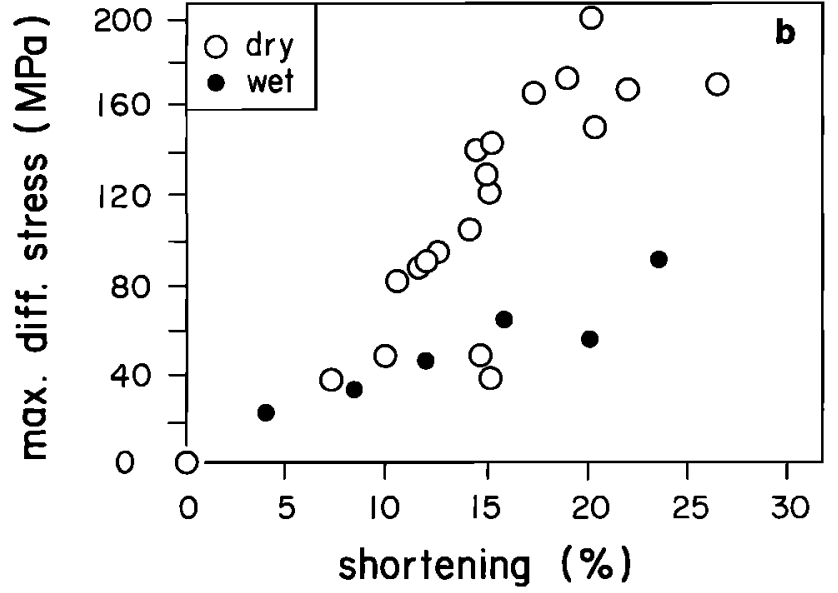

Fig. 2. (a) Stress-strain history for two typical samples, one deformed with a pore fluid present, the other deformed under dry conditions ( $\sigma$ ' is differential stress; $e$ is shortening; $P_{c}$ is confining pressure; $P_{f}$ is pore fluid pressure). Note the dry specimen $\left(P_{f}=0\right)$ undergoes a compactional flow with no clear yield point whereas the wet specimen shows a yield point and a low flow stress of about $60 \mathrm{MPa}$. (b) Summary plot showing maximum differential applied stress as a function of shortening strain, for all samples. Open (solid) symbols represent samples deformed under dry (wet) conditions. (c) Stress relaxation tests for two samples, strained to $5.3 \%$ and $6.9 \%$ respectively. There is a weak dependence of flow stress upon strain rate; the wet $\left(P_{f}=110 \mathrm{MPa}\right)$ specimen is slightly weaker at all strain rates.

Figure 6 correlates coercivity (normalized by $M_{s}$ ) with inverse susceptibility (per unit volume of magnetite) for the deformed samples. As expected theoretically [Stoner and Wohlfarth, 1948; Stacey, 1963] (see also Hodych [1986] and Dunlop et al. [1987]), there is a roughly linear relationship (regression coefficient $R^{2}=$ 0.43). The intercept on the $1 / k$ axis provides an estimate of the average demagnetizing factor $N$; for these samples the intercept value is $0.18 \pm 0.02$. Possible values for $N$ range from 0.13 for two-domain grains up to 0.33 for large multidomain (MD) grains [Dunlop, 1983]. Thus, as found by Dunlop et al [1987], Figure 6 seems to give a rather low estimate for $N$, although the uncertainty is rather large due to the scatter of the data. The slope of the bestfit line for the data of Figure 6 is approximately 10, similar to the slopes reported by Hodych [1986] for a variety of igneous rocks as well as for magnetite. Such a slope is theoretically consistent with both susceptibility and coercivity being controlled dominantly by residual stresses opposing domain wall motion [Hodych, 1986].

Somewhat surprisingly, however, there is virtually no correlation between peak applied stress and the stability of ARM against lowtemperature demagnetization (LTD) (Figure 7). However, it may be noted that the "memory ratio" is weakly correlated with strain: it exceeds 0.5 only for samples that have been shortened by $15 \%$ or more, and it is on average considerably higher for those samples than for those shortened by less than $15 \%$. Previous studies [e.g., Kobayashi and Fuller, 1968; Heider et al., 1990] have generally found that the memory of saturation remanence after LTD was strongly stress-sensitive for a large range of magnetite grain sizes. The apparent lack of stress sensitivity in the ARM memory fraction of these samples may be due to significant residual stresses in the magnetites of our undeformed samples. Figure 8 shows the temperature dependence of $M_{s}$ and $H_{c}$ for an undeformed sample, and for a strongly deformed one. In both cases, $H_{c}(\mathrm{~T})$ varies to a good approximation as $M_{s}{ }^{2}(\mathrm{~T})$, consistent with stress as the principal control on coercivity [e.g., Heider et al., 1987; Xu and Merrill, 1990]. Magnetocrystalline anisotropy, in contrast, varies 


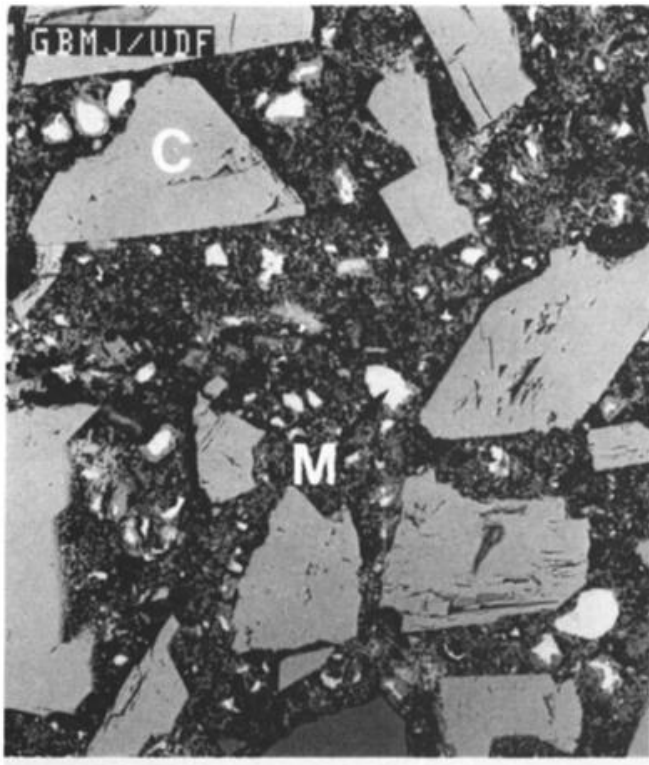

(a)

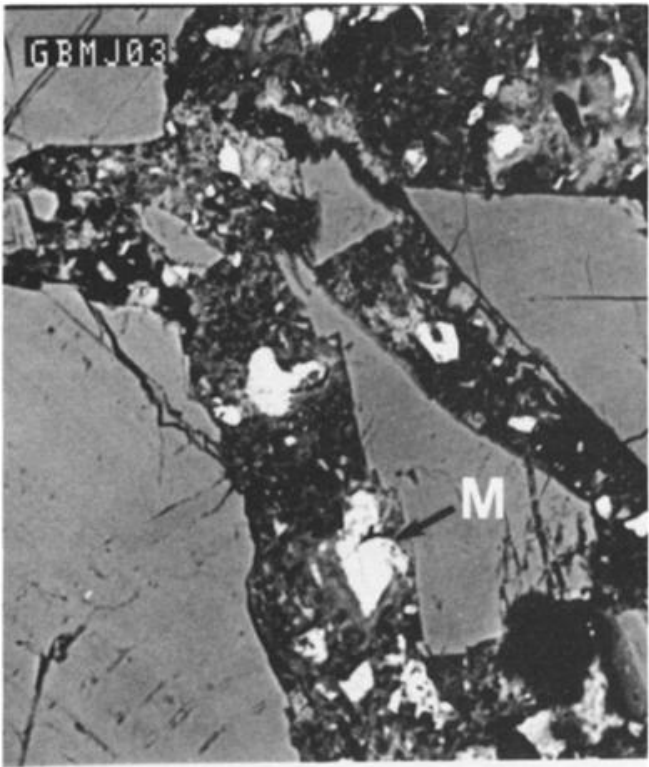

(c)
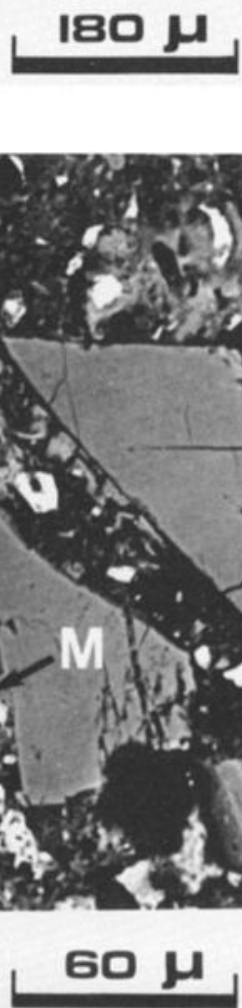

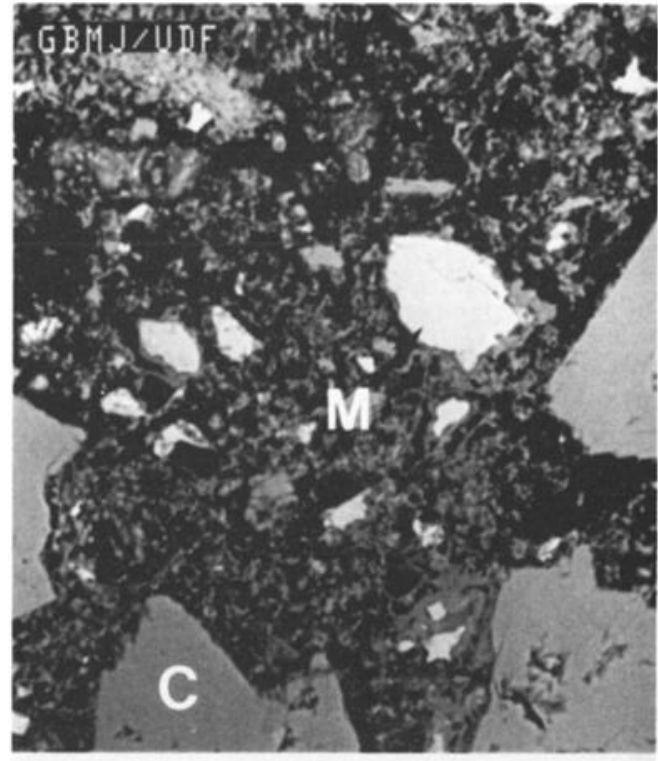

(b)

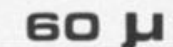

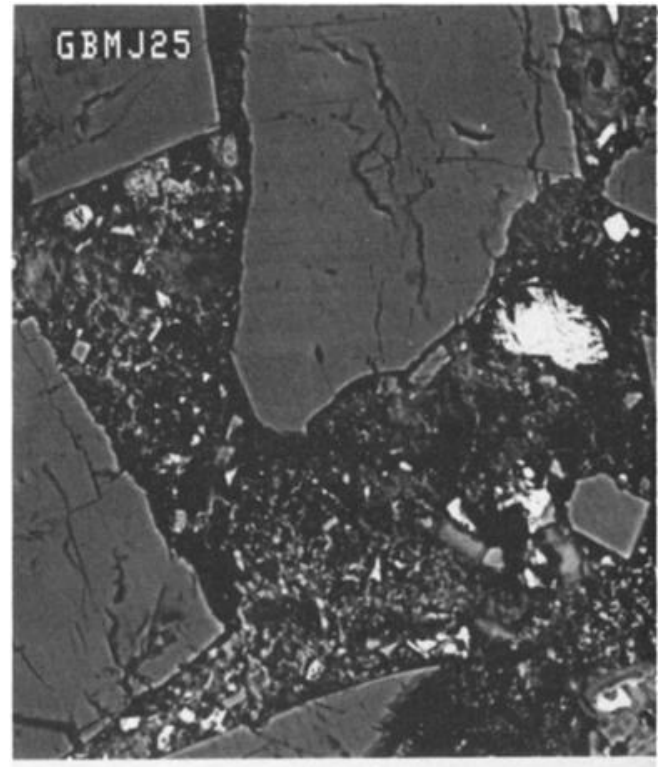

(d)

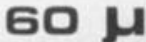

Fig. 3. Scanning electron microscope images of the calcite/cement/magnetite samples. (a) Overview of undeformed aggregate. C is calcite, $\mathrm{M}$ is magnetite. Note well-spaced calcite grains. (b) Close-up of undeformed aggregate. Note the porous cement matrix, and well-spaced calcite clasts. (c) Deformed aggregate, $200 \mathrm{MPa}$ confining pressure, dry conditions, peak differential stress $144 \mathrm{MPa}$, strain $\mathrm{e}=15.3 \%$. Note compaction of cement matrix, and cracking of magnetite (M). (d) Deformed aggregate, $200 \mathrm{MPa}$ confining pressure, $180 \mathrm{MPa}$ pore fluid pressure, peak differential stress $63.5 \mathrm{MPa}$, strain $e=15.8 \%$. Note less compaction of matrix, greater spacing of calcite, and less cracking of magnetite.

with temperature as $M_{s}{ }^{8}(\mathrm{~T})$ [e. g., $O^{\prime}$ Reilly, 1984], and is clearly not the major control on coercivity in these samples (Figure 8).

\section{Changes in Magnetic Remanence With Deformation}

In many samples, both the declination and inclination of the postdeformational remanence were strongly different from the predeformational values (Figure 9). Because the samples were shortened parallel to their cylindrical axes, it is reasonable to expect that only the inclination of the predeformational remanence was directly affected by strain (i.e., by grain reorientation); the declination differences thus indicate the acquisition of an additional component of remanence during the deformation experiment, undoubtedly due in part to the applied stress. However, stepwise AF demagnetization is quite effective at removing this overprint (Figure 9), as also found by Lanham and Fuller [1988]. In almost all cases, AF treatment at $30 \mathrm{mT}$ brings the declination back to its initial $270^{\circ}$ value; thus we can conclude that the stress-related secondary 

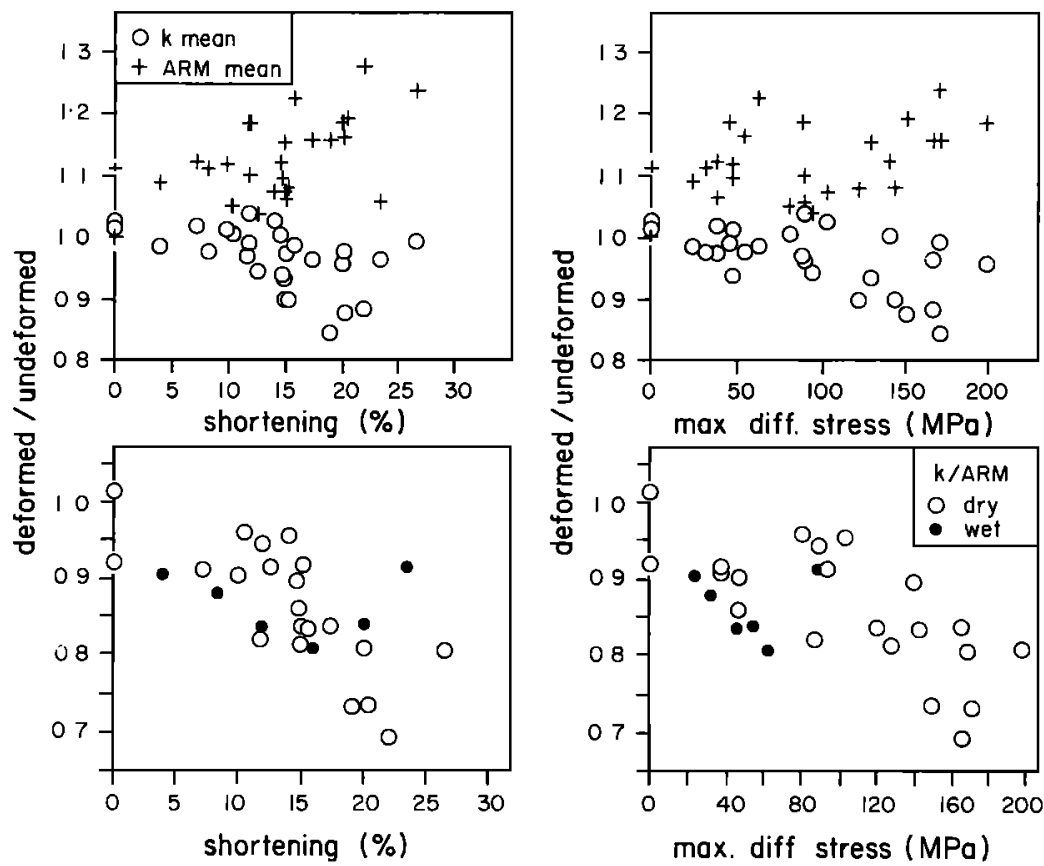

Fig. 4. Changes in bulk magnetic properties with deformation: (top) Mean susceptibility (open circles) and anhysteretic susceptibility (plus symbols) (both normalized to predeformational values) as functions of strain (left) and of peak applied differential stress (right). (bottom) The grain size-sensitive ratio $k$ /ARM (normalized to predeformational values) as a function of strain (left) and of peak applied differential stress (right). Open (solid) symbols indicate dry (wet) deformation.

TABLE 2. Rock Magnetic Properties

\begin{tabular}{|c|c|c|c|c|c|c|c|c|c|c|}
\hline Sample & $10^{-7} \mathrm{~m}^{k_{0}} / \mathrm{kg}$ & $10^{-7} \mathrm{~m}^{k^{3} / \mathrm{kg}} 10^{-5}$ & $\begin{array}{l}\mathrm{ARM}_{0} \\
\mathrm{Am}^{2} / \mathrm{kg}\end{array}$ & $\begin{array}{c}\mathrm{ARM}_{d} \\
10^{-5} \mathrm{Am}^{2} / \mathrm{kg}\end{array}$ & $\begin{array}{c}H_{c 0} \\
\mathrm{mT}\end{array}$ & $\begin{array}{c}H_{c r 0} \\
\mathrm{mT}\end{array}$ & $J_{r s} / J_{s 0}$ & $\begin{array}{c}H_{c d} \\
\mathrm{mT}\end{array}$ & $\begin{array}{c}H_{c r d} \\
\mathrm{mT}\end{array}$ & $J_{r s} / J_{s d}$ \\
\hline 2 & 5.57 & 4.72 & 4.72 & 5.47 & & & & 7.21 & 26.31 & 0.065 \\
\hline 3 & 5.24 & 4.72 & 4.53 & 4.91 & & & & & & \\
\hline 4 & 5.50 & 4.95 & 4.72 & 5.09 & & & & 5.68 & 25.67 & 0.049 \\
\hline 5 & 5.47 & 5.19 & 4.72 & 4.91 & & & & 5.91 & 26.38 & 0.051 \\
\hline 6 & 5.78 & 5.07 & 4.72 & 5.64 & 5.02 & 24.53 & 0.055 & 6.25 & 26.14 & 0.058 \\
\hline 7 & 5.66 & 5.52 & 4.81 & 5.13 & 4.93 & 24.58 & 0.055 & 5.33 & 25.49 & 0.050 \\
\hline 8 & 5.66 & 5.33 & 4.77 & 5.25 & 4.92 & 24.86 & 0.055 & 5.64 & 25.01 & 0.053 \\
\hline 9 & 5.52 & 5.38 & 4.66 & 5.55 & 5.14 & 25.89 & 0.057 & 5.43 & 25.20 & 0.051 \\
\hline 10 & 5.50 & 5.47 & 4.79 & 5.94 & & & & 6.42 & 27.10 & 0.056 \\
\hline 11 & 5.35 & 5.45 & 4.72 & 4.74 & & & & 5.30 & 25.95 & 0.047 \\
\hline 12 & 5.42 & 5.47 & 4.62 & 4.87 & & & & 5.56 & 26.25 & 0.046 \\
\hline 3 & 5.35 & 5.42 & 4.62 & 5.19 & & & & 5.52 & 24.58 & 0.047 \\
\hline 14 & 5.33 & 5.45 & 4.60 & 5.17 & & & & 5.47 & 25.97 & 0.045 \\
\hline 15 & 5.38 & 5.52 & 4.57 & 5.09 & & & & 5.38 & 26.06 & 0.047 \\
\hline 16 & 5.66 & 5.90 & 4.79 & 5.29 & & & & 5.81 & 26.34 & 0.05 \\
\hline 17 & 5.52 & 5.54 & 4.72 & 5.30 & & & & 6.30 & 25.54 & 0.054 \\
\hline 18 & 5.61 & 5.38 & 4.81 & 5.72 & & & & 6.92 & 26.07 & 0.059 \\
\hline 19 & 5.42 & 5.24 & 4.70 & 5.44 & & & & 6.81 & 27.57 & 0.057 \\
\hline 20 & 5.47 & 5.61 & 4.70 & 5.05 & & & & 5.74 & 25.46 & 0.048 \\
\hline 21 & 6.08 & 5.38 & 4.58 & 5.86 & & & & 6.96 & 27.71 & 0.057 \\
\hline 22 & 5.99 & 5.61 & 4.52 & 5.22 & & & & 5.78 & 24.45 & 0.05 \\
\hline 23 & 6.11 & 5.90 & 4.65 & 4.93 & & & & 5.51 & 26.21 & 0.05 \\
\hline 24 & 5.78 & 5.71 & 4.42 & 4.83 & & & & 5.18 & 25.71 & 0.043 \\
\hline 25 & 5.71 & 5.64 & 4.34 & 5.32 & & & & & & \\
\hline 26 & 5.71 & 5.66 & 4.32 & 5.14 & & & & 5.41 & 26.06 & 0.046 \\
\hline 27 & 5.40 & 5.28 & 4.15 & 4.84 & & & & 5.52 & 26.06 & 0.046 \\
\hline 28 & 5.64 & 5.52 & 4.28 & 4.77 & & & & & & \\
\hline
\end{tabular}

Symbols are: $k$, mean susceptibility; ARM, mean anhysteretic remanent magnetization acquired in an alternating field of $100 \mathrm{mT}$ with a bias field of $0.1 \mathrm{mT} ; 0$, original state; $d$, deformed state; $J_{r s}$, saturation remanence; $J_{s}$, saturation magnetization; $H_{c r}$, remanent coercivity; $H_{c}$, coercivity. 

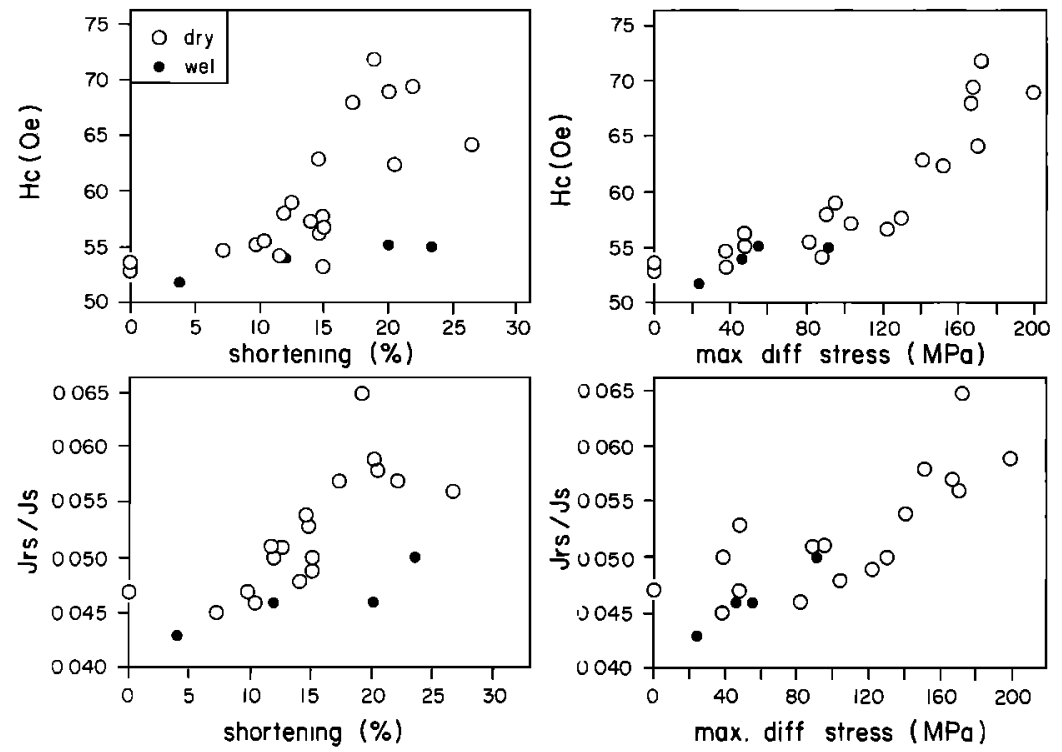

Fig. 5. Hysteresis properties after deformation, as a function of strain (left) and of peak applied differential stress (right). Both coercivity $H_{c}$ and remanence ratio $J_{r s} J_{s}$ increase with degree of deformation. Open (solid) symbols indicate dry (wet) deformation.

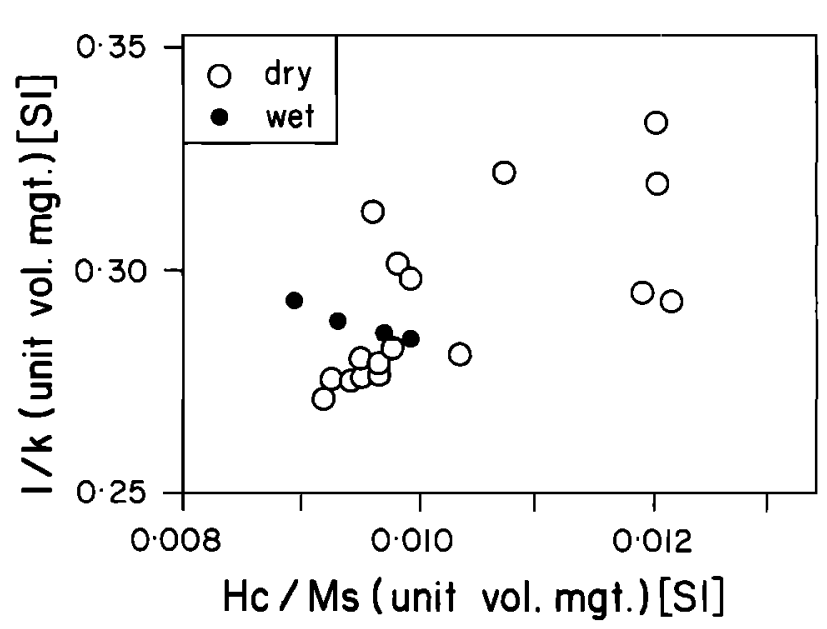

Fig. 6. Inverse susceptibility as a function of the ratio $H_{c} / M_{s}$ for the samples after deformation. Both $k$ and $M_{s}$ are normalized for each sample by the volume of magnetite in the sample. The best-fit line has a slope of about 10 , consistent with stress control of $k$ and $H_{c}$ [Hodych, 1986], and an intercept of 0.18 , the apparent average demagnetizing factor [Dunlop, 1983; Dunlop et al., 1987]. Open (solid) symbols indicate dry (wet) deformation. remanence has been effectively removed, and any remaining difference in inclination is (presumably) directly related to bulk strain, i.e., due to rotation of the magnetite particles.

The orientations of the soft overprints are not consistent, but their magnitudes generally correlate with intensity of deformation (Figure 9). Following removal of the soft component, the magnetization for almost all of the samples followed straight trajectories toward the origin; inclinations of these linear segments were calculated by principal component analysis [Kirschvink, 1980]. For the samples that had been magnetically saturated before acquiring their ARM, the magnetization decays not toward the origin, but instead to the direction of saturation remanence. This is due to the presence of magnetic carriers with coercivities high enough to be unaffected by ARM acquisition and AF demagnetization. The ARM appears to be somewhat "underprinted" by the saturation remanence: the inclination of the remanence removed above about 60 or $70 \mathrm{mT}$ is considerably shallower than that removed at lower AFs (Figure 9c). The inclination of the surviving ARM in these samples was calculated by fitting a line to the interval between about $20 \mathrm{mT}$ and about 60 or $70 \mathrm{mT}$.

The change in inclination of the cleaned remanence as a function of strain is shown in Figure 10 . It appears that there is a
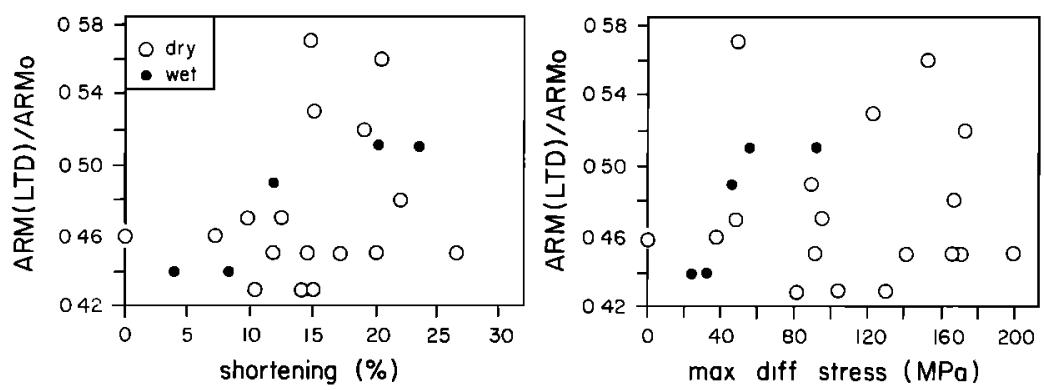

Fig. 7. Anhysteretic remanent magnetization (ARM) "memory ratio" (fraction of ARM retained after low-temperature demagnetization, or LTD), as a function of shortening strain (left) and of peak applied stress (right). Open (solid) symbols indicate dry (wet) deformation. 

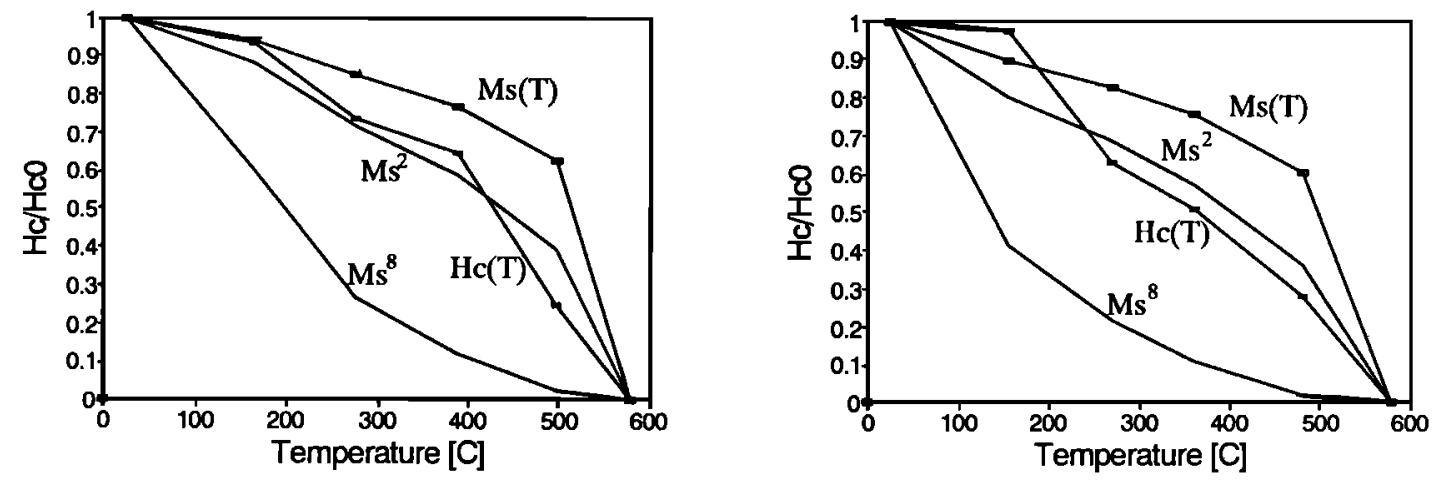

Fig. 8. Temperature-dependence of hysteresis properties for a weakly-deformed (left) and a strongly-deformed (right) sample. Note that in each case, $H_{c}(T)$ varies as $M_{s}^{2}(T)$, indicating stress control of coercivity. For magnetocrystalline anisotropy, $H_{c}(T)$ varies as $M_{s}^{8}(T)$, shown for reference.

\subsection{2}

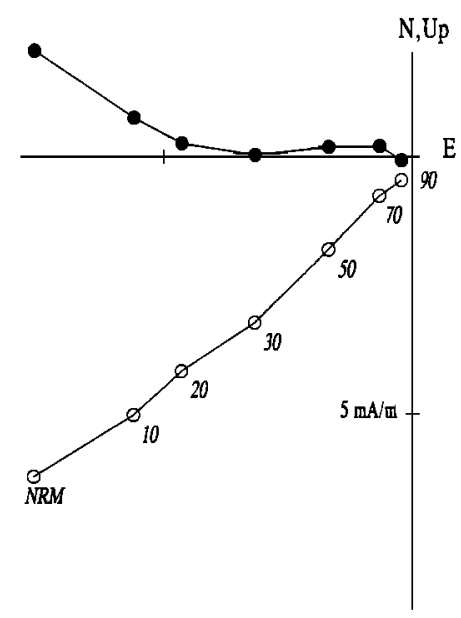

2.19

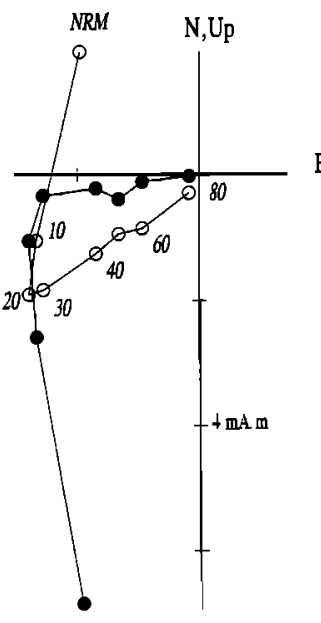

$\operatorname{cs} 9.12$

C

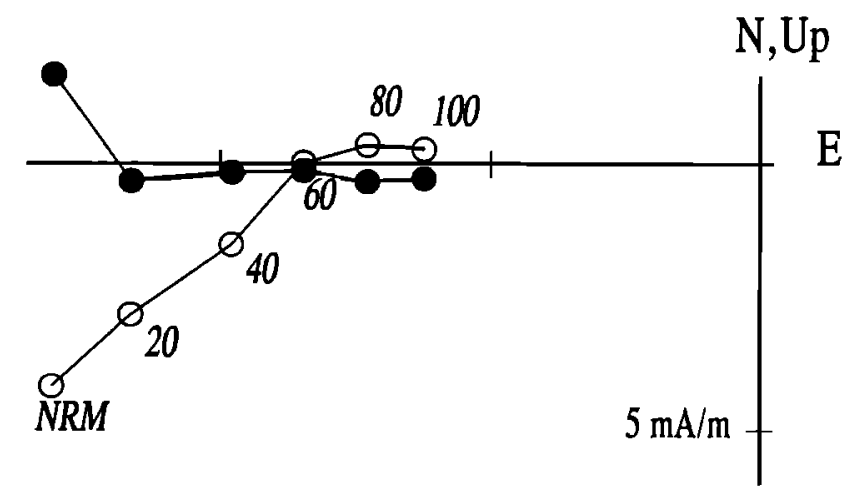

$\operatorname{cs} 6.20$

10.27

b

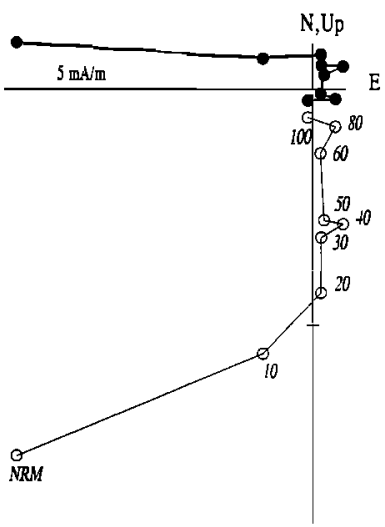

11.h

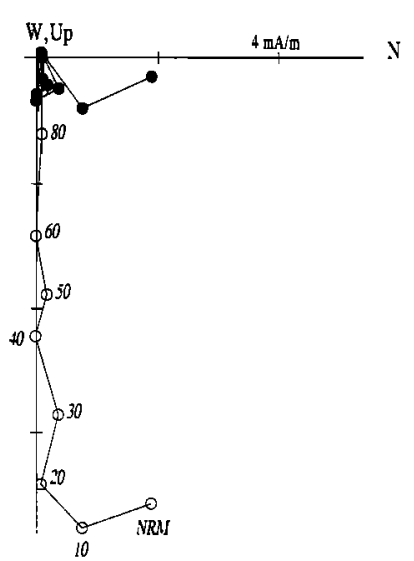

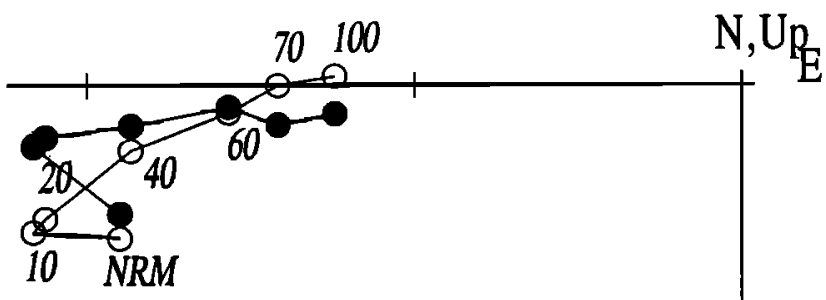

$5 \mathrm{~mA} / \mathrm{m}$

Fig. 9. Orthogonal vector plots [Zijderveld, 1967] showing behavior of postdeformational remanence during AF demagnetization. Open symbols, labeled with af values in milliteslas, represent projections of the magnetization vector onto the vertical N-S or E-W plane; solid symbols are projections on the horizontal plane. In each case, removal of a low-coercivity secondary (stress-related) component of remanence (not systematically oriented), is followed by removal of the predeformational component, slightly flattened. The secondary component is larger in more strongly deformed samples. (a) Samples with a predeformational inclination of $45^{\circ}$ (sample 16, shortened by $12 \%$; sample 2, shortened by 19\%). (b) Samples with initially vertical remanence (sample $10,27 \%$ shortening; sample 11, hydrastatic stress only). (c) Samples subjected to saturating horizontal fields during initial hysteresis measurements, then given an ARM with $45^{\circ}$ inclination before deformation. 

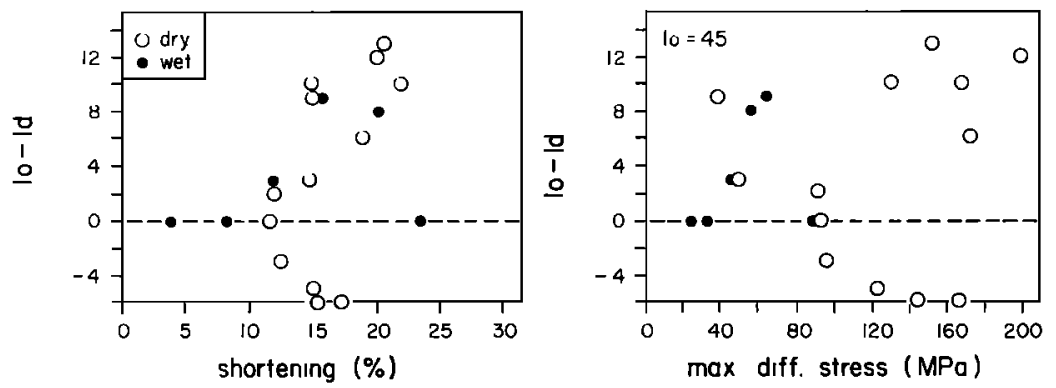

Fig. 10. Summary of inclination changes due to deformation, after af cleaning. $\Delta I\left(=I_{0}-I_{d}\right)$ as a function of shortening (left) and as a function of peak applied stress (right). Open (solid) symbols indicate dry (wet) deformation.

"threshhold strain" of about $10 \%$, below which there are essentially no changes. At strains above $10 \%$ there is a rather surprising pattern. Most of the samples exhibit shallower inclinations after deformation, with the amount of shallowing $\left(\Delta I=I_{o}-I_{d}\right)$ directly related to the amount of strain. However there are four samples ( 3 , 4,5 , and 19) with inclinations that are actually steeper after deformation, and the inclination changes again appear to be a linear function of strain. Similar behavior has been found by Borradaile and Mothersill [1991] and by Borradaile [1992] for multicomponent IRMs, but it was not expected for these samples, which carry a single-component ARM. We will consider this further in the discussion section.

Overall, inclination changes appear to correlate more strongly with bulk strain than with peak applied stress. This suggests that the remanence is reoriented primarily by rotation of the magnetite grains, rather than by the intracrystalline changes that have given rise to the magnetic hardening. The samples deformed under wet

TABLE 3. Remanence Characteristics

\begin{tabular}{|c|c|c|c|c|c|c|}
\hline Sample & $I_{0}$ & $I_{d 20}$ & $J_{z 0}$ & $J_{z d 20}$ & $I_{0}-I_{d}$ & $J_{z d} / J_{0}$ \\
\hline 2 & 42 & 36 & 17.2 & 1.86 & 6 & 0.108 \\
\hline 3 & 43 & 49 & 18.0 & 2.53 & -6 & 0.141 \\
\hline 4 & 42 & 47 & 16.7 & 4.17 & -5 & 0.250 \\
\hline 5 & 44 & 47 & 17.6 & 3.59 & -3 & 0.204 \\
\hline 6 & 44 & 31 & 17.5 & 2.01 & 13 & 0.115 \\
\hline 7 & 43 & 34 & 18.0 & 2.58 & 9 & 0.143 \\
\hline 8 & 43 & 40 & 18.4 & 2.86 & 3 & 0.155 \\
\hline 9 & 43 & 43 & 17.6 & 2.84 & 0 & 0.161 \\
\hline 10 & 90 & & 25.4 & 4.31 & & 0.170 \\
\hline 11 & 90 & & & 6.84 & & \\
\hline 12 & 90 & & 25.0 & 5.87 & & 0.235 \\
\hline 13 & 90 & & 25.2 & 6.13 & & 0.243 \\
\hline 14 & 90 & & 24.3 & 6.16 & & 0.253 \\
\hline 15 & 90 & & 24.0 & 6.61 & & 0.275 \\
\hline 16 & 46 & 44 & 18.1 & 4.18 & 2 & 0.232 \\
\hline 17 & 44 & & 17.2 & & & \\
\hline 18 & 45 & 33 & 18.4 & 2.14 & 12 & 0.116 \\
\hline 19 & 46 & 52 & 17.8 & 3.96 & -6 & 0.223 \\
\hline 20 & 45 & & 17.8 & 3.32 & & 0.186 \\
\hline 21 & 46 & 36 & 18.4 & 2.95 & 10 & 0.160 \\
\hline 22 & 43 & 33 & 17.9 & 3.24 & 10 & 0.181 \\
\hline 23 & 43 & 43 & 18.2 & 3.97 & 0 & 0.218 \\
\hline 24 & 41 & 41 & 16.6 & 4.29 & 0 & 0.258 \\
\hline 25 & 43 & 34 & 17.2 & 3.50 & 9 & 0.203 \\
\hline 26 & 43 & 40 & 17.0 & 3.30 & 3 & 0.194 \\
\hline 27 & 41 & 33 & 15.7 & 3.41 & 8 & 0.217 \\
\hline 28 & 48 & 48 & 18.3 & 5.11 & 0 & 0.279 \\
\hline
\end{tabular}

Symbols are: $I$, inclination (degrees); $J_{z}$, axial remanence component $\left(10^{-8} \mathrm{Am}^{2}\right)$; 0, original state; $d$, deformed state; 20 , demagnetized in $20 \mathrm{mT}$ alternating field. conditions appear to behave somewhat differently at high strains; final inclination for the most strongly deformed of these samples (sample 23) is essentially identical to initial inclination (Table 3).

It is useful to compare these results with the simple "nonmaterial line" or "passive linear marker" model, in which the remanence is considered to behave as a line drawn on the sample [e.g., Morash and Bonhommet, 1981; Kligfield et al., 1983; Cogné and Perroud, 1985, 1987]. This is described by

$$
\frac{\tan I_{d}}{\tan I_{0}}=\frac{Z}{X}=\frac{\left(1+e_{3}\right)}{\left(1+e_{1}\right)}
$$

This behavior is represented by the dashed line in Figure 11. Figure 11 shows that up to strains of $10 \%(Z / X \sim 0.9)$, the remanence rotates much more slowly than a "passive line," remaining close to the initial inclinations. At higher strains, the remanence rotates much more rapidly than a material line, and the data slope more steeply than the dashed reference line. In addition, the steeper postdeformational remanence found in some samples clearly indicates behavior that is very different (qualitatively as well as quantitatively) from that of a material line.

The component of remanence parallel to the shortening axis $\left(J_{z}\right)$ is considered separately in Figure 12 . In each case the postdeformational vertical component of remanence (after $30 \mathrm{mT}$ AF treatment) is normalized by the vertical component of the initial remanence (untreated). Here strain is plotted as $1+e_{3}$

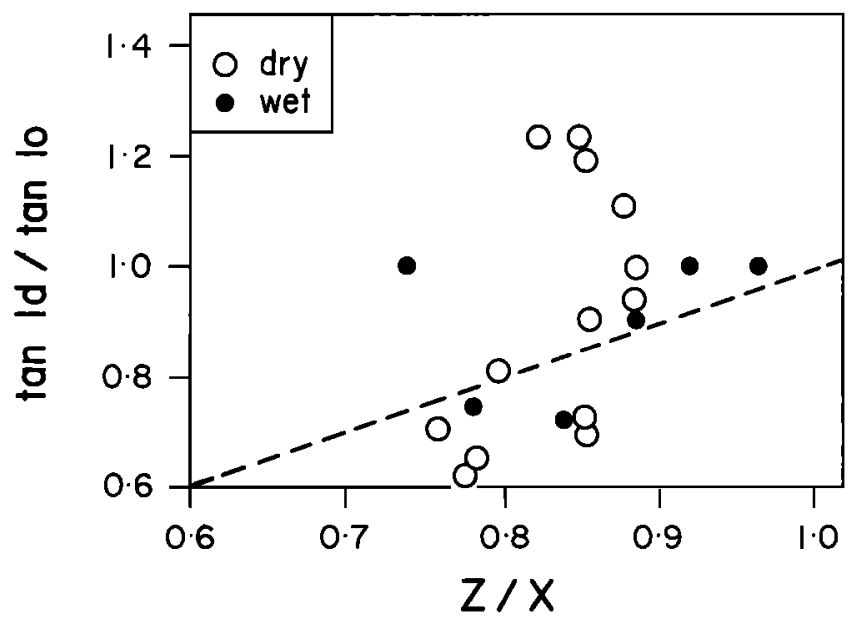

Fig. 11. Comparison of postdeformational inclinations with those predicted by the "passive line" model: $\tan \left(I_{d}\right) / \tan \left(I_{0}\right)=Z J X$. Note that strain increases to the left in this plot. For these samples, inclination changes more slowly at low strains than a material line, but more rapidly at higher strains. Open (solid) symbols indicate dry (wet) deformation. 

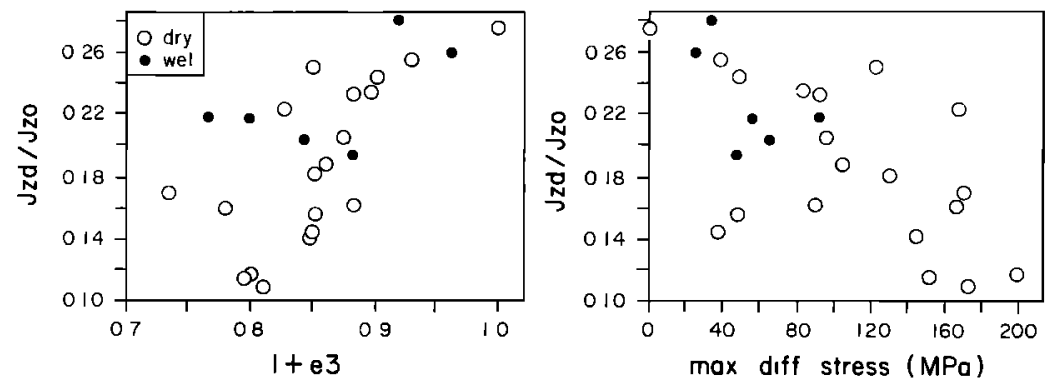

Fig. 12. Component of cleaned postdeformational remanence parallel to the shortening axis $\left(J_{z d}\right)$ normalized by the vertical component of the initial (untreated) remanence $\left(J_{z 0}\right)$, as a function of shortening strain (left) and of peak applied stress (right). Strain is plotted as $1+e_{3}\left(=Z=l / l_{0}\right)$, which is the material analog of the remanence ratio. Note that strain increases to the left in this plot. Open (solid) symbols indicate dry (wet) deformation.

$\left(=Z=l / l_{0}\right)$, which is the material analog of the remanence ratio. Several important observations may be made.

First, all of the deformed samples have smaller normalized vertical components of remanence than the undeformed samples. Thus, in the samples with steeper inclinations after deformation (Figures 10 and 11 and Table 3), the remanence is reduced parallel to shortening, but it is reduced even more strongly perpendicular to shortening. Similar observations have been made by Borradaile and Mothersill [1989, 1991] and by Borradaile [1992], using strong-field multicomponent IRM. Of the four samples with steepened postdeformational remanence, two have unusually large fractions of their initial $J_{Z}$ remaining ( 4 and 19), whereas the other two show the same fractional retention as the other samples. It is interesting to note that of these four samples, three of them $(3,4$, and 5) had maximum $k_{a}$ axes (before deformation) close to, but slightly steeper than, the predeformational remanence orientation, while the fourth (19) had an initial $k_{a}$ maximum axis close to vertical. Thus the remanence in each of the "steepened" samples has rotated toward the direction of particle alignment, as indicated by ARM anisotropy.

A second observation to be made from Figure 12 is that the "threshhold" of $10 \%$ shortening $\left(1+e_{3}=0.9\right)$ is very apparent; normalized intensities diminish only slightly between 0 and $10 \%$ shortening and then decrease (for most of the samples) by a factor of 2 between $10 \%$ and $20 \%$ strain. The samples with initially vertical remanence follow the same general trend as those with inclined initial remanences, as do those that had previously been exposed to saturating horizontal fields (Table 3). The trend of the wet-deformation data is somewhat different from that of the dry data (Table 3): the most strongly deformed wet samples (23 and 27) retained a very large fraction of their initial $J_{z}$; maximum relative remanence loss for the wet samples occurred between $10 \%$ and $15 \%$ shortening, along the dry data trend.

\section{Magnetic Anisotropy as a Function of Stress and of Strain}

Figure 13 shows the orientations and axial ratios of $\left[k_{1}\right]$ and $\left[\mathrm{k}_{\mathrm{a}}\right]$ after deformation. All but the most weakly deformed or undeformed samples have oblate magnetic ellipsoids that are essentially coaxial with the horizontally oblate strain ellipsoid.

The magnitude of susceptibility anisotropy as a function of strain is shown in Figure 14 and listed in Table 4. Two observations are immediately apparent. First, there is a fairly strong linear relationship between the ratio $k_{\max } / k_{\min }$ and strain; second, a "threshhold strain" of about $10 \%$ separates data points arrayed along a line of very shallow slope from data lying along a relatively steep slope. Small anisotropies of $5 \%$ to $10 \%(\max / \min \leq 1.10)$ characterize the undeformed samples as well as those with strains

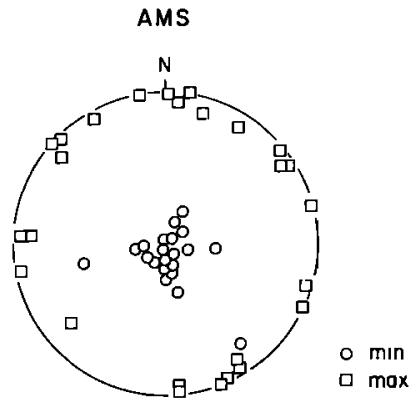

a)

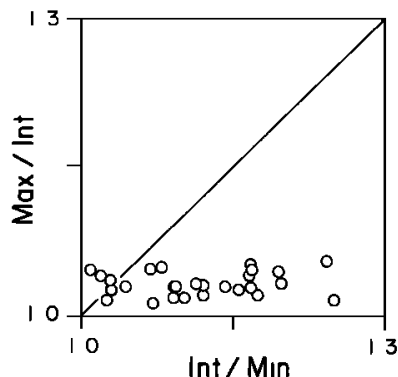

b)

Fig. 13. Equal-area and Flinn-type plots illustrating orientations and shapes of AMS and ARM ellipsoids after deformation: note larger anisotropies and strong vertical grouping of minimum axes, parallel to the axis of shortening.

up to $10 \%$; anisotropies reach a maximum of more than $30 \%$ in samples with about $20 \%$ strain.

Samples deformed with a pore fluid present (at relatively low differential stresses) have anisotropy ratios very close to those of samples deformed by the same amount under dry conditions (at much higher differential stresses). Thus it is clear that the AMS is controlled primarily by mechanisms associated with bulk strain, rather than by stress. AMS in these samples arises dominantly as a result of rotation of the magnetite particles accompanying strain, rather than by development of metastable "domain anisotropies" due to stress, as envisioned by Park et al. [1988]. Repeat measurements of AMS for a few specimens after AF demagnetization showed negligible changes.

Figure 15 shows ARM anisotropy as a function of strain and as a function of peak applied differential stress. In contrast to the AMS results, the ARM anisotropies attained in the wet deformation experiments are distinctly lower than those resulting from the same amount of dry strain (Table 5). Thus the ARM anisotropy ratio varies somewhat more systematically as a function of peak applied 

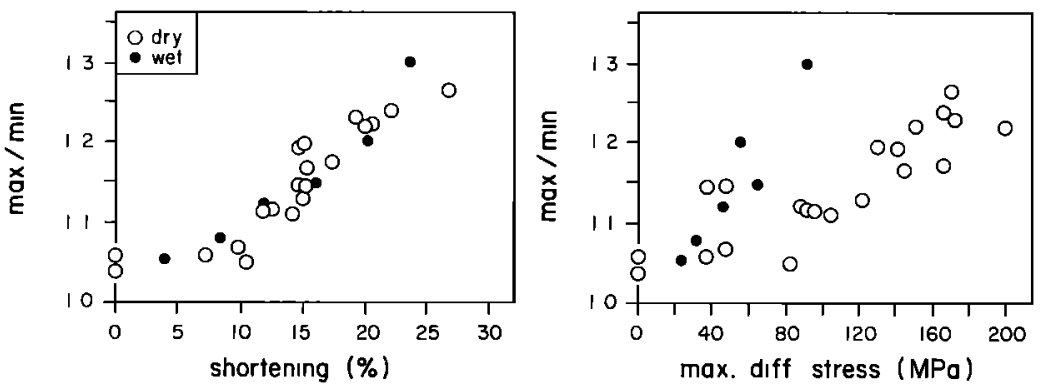

Fig. 14. Susceptibility anisotropy as a function of shortening strain (left) and of applied stress (right). Open (solid) symbols indicate dry (wet) deformation.

stress than as a function of strain. This suggests that the ARM anisotropy of individual particles is significantly increased by the applied stress.

\section{Changes in Magnetic Anisotropy With Deformation}

An important advantage of experimental as opposed to empirical studies is that the initial magnetic anisotropy is known; it is therefore possible to directly evaluate the change in the magnetic fabric. In effect, one can compare the shapes of the initial and final magnetic ellipsoids, and calculate the shape change or "magnetic strain":

$$
\left[k_{\text {deformed }}\right]=[d]\left[k_{\text {undeformed }}\right]
$$

whence

$$
[d]=\left[k_{\text {undeformed }}\right]\left[k_{\text {deformed }}\right]^{-1}
$$

[Hrouda, 1992]. The ellipsoid described by the matrix [d] is analogous to the strain ellipsoid, but it refers to the shape change of the magnetic ellipsoid rather than that of the material itself.

Figure 16 compares the minimum principal length of the "magnetic strain ellipsoid" ( $\left.d_{3}\right)$ for susceptibility with its material analog $\left(\mathrm{Z}=1+\mathrm{e}_{3}\right)$. In all cases $d_{3}$ was essentially vertical and identical in magnitude to $d_{33}$. The dashed line represents the hypothetical case in which the magnetic ellipsoid is deformed in exactly the same way as the material, i.e., the magnetic ellipsoids act as passive strain markers. It is obvious that all of the data lie significantly to the left of this line, indicating that the susceptibility ellipsoids are less deformed than the material. It is interesting to point out, however, that the data generally define a linear trend nearly parallel to the dotted line in the figure, and that this linear trend intercepts the top of the figure at about $10 \%$ strain $\left(1+e_{3}=0.9\right)$. This indicates that strains of $10 \%$ or less have had negligible effect on the shapes of the AMS ellipsoids (as could be surmised from Figure 14); moreover for strains exceeding $10 \%$, the magnetic susceptibility ellipsoids are deformed at essentially the same rate as the material.

The results of the wet deformation runs show the same pattern as the dry data when plotted as a function of strain, but a very different pattern as a function of applied differential stress (Figure 16). The wet samples exhibit much larger changes in AMS (i.e., smaller values of $d_{33}$ ) at a given stress than the dry samples do. This again leads to the conclusion that the development of AMS in these samples is controlled dominantly by the effects of bulk strain (particularly reorientation of magnetite grains) rather than by those of stress.
TABLE 4. Susceptibility Anisotropy

\begin{tabular}{rrrrrrr}
\hline Sample & $k_{z d} / k_{m}$ & $k_{z d} / k_{z 0}$ & $d_{33}$ & $P_{0}$ & $P_{d}$ & $P_{d}-P_{0}$ \\
\hline 2 & 0.878 & 0.883 & 0.872 & 1.072 & 1.230 & 0.158 \\
3 & 0.915 & 0.913 & 0.912 & 1.048 & 1.165 & 0.117 \\
4 & 0.936 & 0.924 & 0.923 & 1.048 & 1.129 & 0.081 \\
5 & 0.946 & 0.923 & 0.922 & 1.063 & 1.116 & 0.053 \\
6 & 0.886 & & & & 1.220 & \\
7 & 0.920 & & & & 1.143 & \\
8 & 0.928 & & & & 1.146 & \\
9 & 0.932 & & & & 1.119 & \\
10 & 0.855 & 0.863 & 0.862 & 1.022 & 1.263 & 0.241 \\
11 & 0.999 & 0.997 & 0.995 & 1.050 & 1.040 & -0.010 \\
12 & 0.983 & 0.971 & 0.964 & 1.049 & 1.051 & 0.002 \\
13 & 0.973 & 0.957 & 0.956 & 1.070 & 1.069 & -0.001 \\
14 & 0.976 & 0.980 & 0.976 & 1.037 & 1.059 & 0.022 \\
15 & 0.977 & 0.982 & 0.980 & 1.027 & 1.060 & 0.033 \\
16 & 0.945 & 0.986 & & 1.045 & 1.116 & 0.071 \\
17 & 0.903 & 0.919 & & 1.046 & 1.191 & 0.145 \\
18 & 0.892 & 0.857 & & 1.068 & 1.218 & 0.150 \\
19 & 0.910 & 0.883 & & 1.036 & 1.174 & 0.138 \\
20 & 0.941 & 0.955 & & 1.027 & 1.110 & 0.083 \\
21 & 0.885 & 0.878 & 0.868 & 1.087 & 1.238 & 0.151 \\
22 & 0.900 & 0.927 & 0.926 & 1.087 & 1.195 & 0.108 \\
23 & 0.853 & 0.869 & 0.868 & 1.065 & 1.300 & 0.235 \\
24 & 0.984 & 0.972 & 0.971 & 1.055 & 1.055 & 0.000 \\
25 & 0.921 & 0.922 & 0.922 & 1.034 & 1.147 & 0.113 \\
26 & 0.935 & 0.934 & 0.931 & 1.035 & 1.122 & 0.087 \\
27 & 0.902 & 0.892 & 0.890 & 1.063 & 1.201 & 0.138 \\
28 & 0.958 & 0.956 & 0.951 & 1.071 & 1.081 & 0.010 \\
& & & & & & \\
\hline
\end{tabular}

Symbols are: $k_{z}$, axial susceptibility; $k_{m}$, mean susceptibility; $[\mathrm{d}]=\left[\mathrm{k}_{0}\right]^{-1}\left[\mathrm{k}_{\mathrm{d}}\right]$ (see text); $P, \max / \mathrm{min} ; 0$, original state; $d$, deformed state

In contrast, ARM anisotropy appears to be overwhelmingly controlled by the magnitude of applied differential stress. Figure 17 illustrates the changes in the shapes of the ARM ellipsoids as a function of both stress and strain. The dry data, when considered separately, show a similar pattern to the AMS data, defining a roughly linear trend with unit slope (i.e., parallel to the passive marker reference line) intercepting the top of the diagram at about 0.9. The wet-sample data are also arrayed along a linear trend in Figure 17, but with a slope of about 0.5 (in comparison with the unit slope for the dry data). However the wet and dry data are neatly superimposed when plotted as a function of peak applied differential stress.

\section{DISCUSSION}

The magnetic properties of our synthetic samples have been altered in important and rather complex ways by the stresses and 

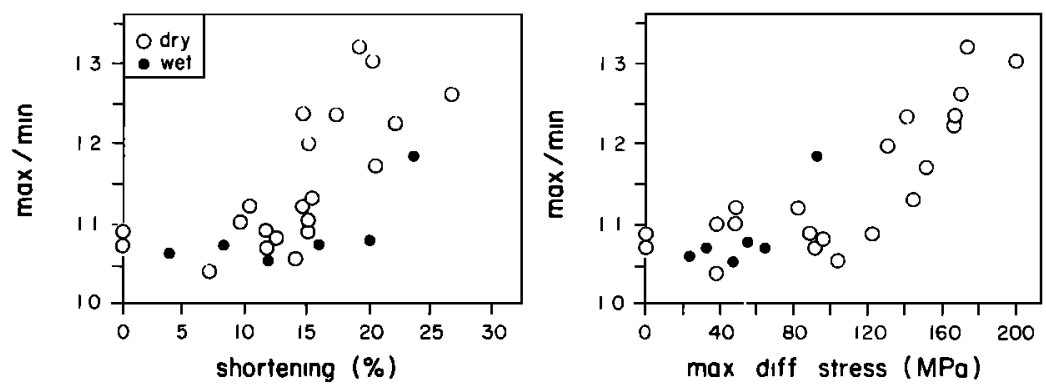

Fig. 15. Anisotropy of anhysteretic remanent magnetization (ARM) as a function of shortening strain (left) and of applied stress (right). Open (solid) symbols indicate dry (wet) deformation.

TABLE 5. Anhysteretic Remanence Anisotropy

\begin{tabular}{|c|c|c|c|c|c|c|}
\hline Sample & $A_{z d} / A_{m}$ & $A_{z d} / A_{z 0}$ & $d_{33}$ & $P_{0}$ & $P_{d}$ & $P_{d}-P_{0}$ \\
\hline 2 & 0.848 & 0.846 & 0.837 & 1.32 & 1.07 & 0.25 \\
\hline 3 & 0.939 & 0.928 & 0.916 & 1.13 & 1.14 & -0.01 \\
\hline 4 & 0.952 & 0.922 & 0.904 & 1.09 & 1.14 & -0.05 \\
\hline 5 & 0.952 & 0.939 & 0.937 & 1.08 & 1.19 & -0.11 \\
\hline 6 & 0.911 & 0.936 & 0.923 & 1.17 & 1.04 & 0.13 \\
\hline 7 & 0.949 & 0.983 & 0.980 & 1.10 & 1.07 & 0.03 \\
\hline 8 & 0.948 & 0.967 & 0.956 & 1.12 & 1.12 & 0.00 \\
\hline 9 & 0.948 & 0.968 & 0.952 & 1.09 & 1.06 & 0.03 \\
\hline 10 & 0.860 & 0.860 & 0.858 & 1.26 & 1.09 & 0.17 \\
\hline 11 & 0.968 & 1.07 & & & & \\
\hline 12 & 0.953 & 0.973 & 0.961 & 1.12 & 1.11 & 0.01 \\
\hline 13 & 0.937 & 0.956 & 0.954 & 1.10 & 1.03 & 0.07 \\
\hline 14 & 0.961 & 0.984 & 0.951 & 1.04 & 1.07 & -0.03 \\
\hline 15 & 0.982 & 1.009 & 0.967 & 1.09 & 1.07 & 0.02 \\
\hline 16 & 0.971 & 0.971 & 0.969 & 1.07 & 1.05 & 0.02 \\
\hline 17 & 0.883 & 0.900 & 0.896 & 1.24 & 1.08 & 0.16 \\
\hline 18 & 0.862 & 0.856 & 0.851 & 1.30 & 1.12 & 0.18 \\
\hline 19 & 0.886 & 0.871 & 0.869 & 1.23 & 1.04 & 0.20 \\
\hline 20 & 0.982 & 1.06 & & & & \\
\hline 21 & 0.884 & 0.877 & 0.868 & 1.22 & 1.15 & 0.08 \\
\hline 22 & 0.911 & 0.946 & 0.946 & 1.20 & 1.13 & 0.07 \\
\hline 23 & 0.904 & 0.928 & 0.923 & 1.18 & 1.10 & 0.08 \\
\hline 24 & 1.014 & 1.004 & 0.945 & 1.06 & 1.10 & -0.04 \\
\hline 25 & 0.972 & 0.953 & 0.941 & 1.07 & 1.09 & -0.01 \\
\hline 26 & 0.974 & 0.961 & 0.953 & 1.05 & 1.07 & -0.02 \\
\hline 27 & 0.955 & 0.942 & 0.927 & 1.08 & 1.07 & 0.01 \\
\hline 28 & 0.984 & 0.982 & 0.955 & 1.07 & 1.14 & -0.07 \\
\hline
\end{tabular}

Symbols are: $A_{z}$, axial ARM; $A_{m}$, mean ARM; $[\mathrm{d}]=\left[\mathrm{A}_{0}\right]^{-1}\left[\mathrm{~A}_{\mathrm{d}}\right]$ (see text); $P, \max / \mathrm{min} ; 0$, original state; $d$, deformed state strains of laboratory deformation. Several phenomena are undoubtedly important in producing these changes. Rotation and reorientation of the magnetite grains probably contribute to the changes in remanence inclination as well as to the changes in AMS and ARM anisotropy. Deformation microstructures produced within the magnetite grains, such as dislocation pile-ups, may contribute to these effects as well, particularly for ARM anisotropy. The increase in magnetic hardness, manifested by increased $H_{c}$, $J_{r s} / J_{s}$, and mean ARM, and decreased mean susceptibility, must involve some type of microscopic deformation of the magnetite grains, rather than particle reorientation. Similar changes occur with decreasing grain size in magnetites; some of the changes we observe may thus be due brittle failure and grain size reduction. However it seems more likely that increasing defect concentration is the major factor. Here we will consider each of the observed changes in some detail.

\section{Changes in Rock Magnetic Properties}

$X u$ and Merrill $[1989,1990]$ calculate that microcoercivity $h_{c}$ increases as the square root of $\boldsymbol{n}$, where $\boldsymbol{n}$ is the number of defects within a domain wall (thus $h_{c}$ depends upon defect concentration and wall thickness). Defect densities in magnetite range from about $10^{5} \mathrm{~cm}^{-2}$ in stress-free particles precipitated hydrothermally [Heider et al., 1987] or from a gel [Amin et al., 1987], up to more than $10^{12} \mathrm{~cm}^{-2}$ in crushed or deformed grains [Baleyev and Absalyamov, 1983]. According to theory, the macroscopic or measurable coercivity $H_{c}$ in grains with low defect concentrations is proportional to $h_{c} 2$ and therefore to $n$, whereas in particles with high defect concentration, $H_{c}$ is linearly proportional to $h_{c}$, and therefore to $n^{1 / 2}$ [Xu and Merrill, 1990]. Baleyev and Absalyamov
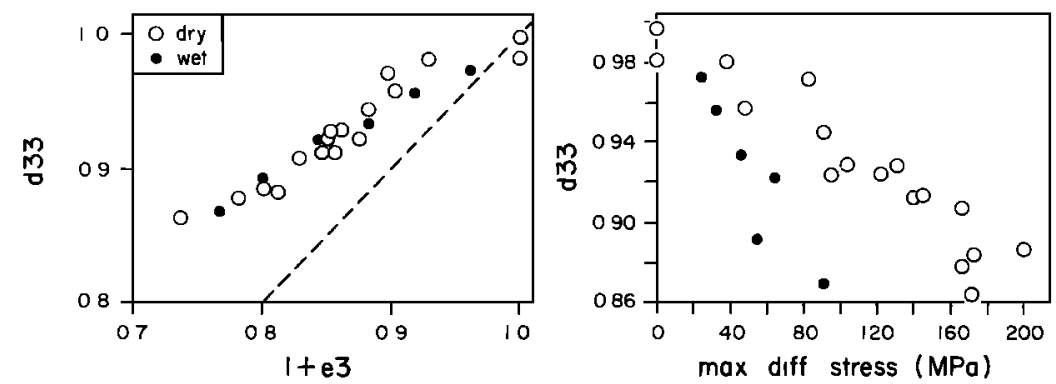

Fig. 16. Change in susceptibility anisotropy as a function of shortening (left) and of peak applied stress (right). The change in AMS is described by the matrix [d], whose vertical component $d_{33}$ is analogous to the strain ratio $Z=1+e$. The dashed line in the plot on the left shows the behavior of passive strain markers. Note that strain increases to the left in this plot. Open (solid) symbols indicate dry (wet) deformation. 

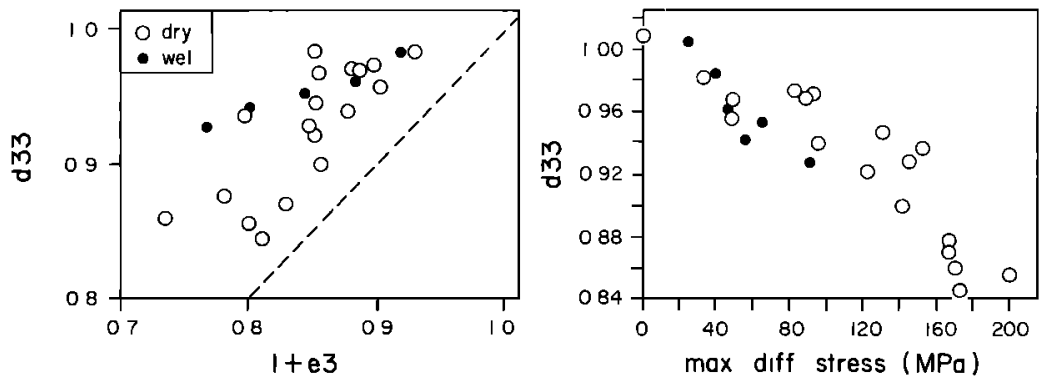

Fig. 17. Change in ARM anisotropy as a function of shortening (left) and of peak applied stress (right). The change in ARM anisotropy is described by the matrix [d], as for AMS (Fig 16). Note that strain increases to the left in this plot. Open (solid) symbols indicate dry (wet) deformation.

[1983] found in laboratory deformation experiments that defect density $n$ first increased linearly with stress, and then as the square of stress. They also reported that $H_{c}$ in their samples was proportional to $n^{1 / 2}$, consistent with the calculations of $X u$ and Merrill [1989, 1990].

In this study we find that $H_{c}$ increases systematically with applied differential stress, slowly at first and then more rapidly with higher stresses (Figure 5). If, as seems likely, this is due to increasing defect concentration (with $H_{c}$ proportional to $n 1 / 2$ ), it implies that $n$ increases very slowly at low stresses, and more rapidly above about $150 \mathrm{MPa}$. Above this point, $H_{c}$ is nearly proportional to peak applied stress (i.e., linear with an intercept of zero), as would be expected for $H_{c}$ proportional to the square root of defect density $(n 1 / 2)$ and $n$ proportional to the square of differential stress $\left(\sigma_{d}{ }^{2}\right)$. A possible explanation for the sudden change in the rate of increase in $H_{c}$ at about $150 \mathrm{MPa}$ is that these magnetites suffered stresses approaching that magnitude during their initial preparation (crushing and seiving), with resulting defects that determined the initial sample properties; application of lower stresses in our experiments produces relatively small changes in $H_{c}$, whereas application of higher stresses causes dramatic changes. Perhaps a better explanation for this apparent discontinuity in stress dependence may be found in Figure $2 b$, where it can be seen that differential stresses exceeding $150 \mathrm{MPa}$ were applied only to samples shortened by more than $15 \%$ (i.e., beyond final porosity closure). After closure of porosity, the applied stress may have been transmitted more efficiently to the magnetite particles in the sample interior. A final possible explanation for the observed dependence of $H_{c}$ on applied stress is that there may be a threshbold stress for increasing defect density in magnetite.

Intrinsic susceptibility of ferrimagnetic material is in general inversely related to coercivity:

$$
k_{i} H_{c}=\text { const }
$$

[Stacey and Banerjee, 1974]. The measured or observed susceptibility $k_{o}$ of ferrimagnetic particles is determined by their intrinsic susceptibility and by self-demagnetization. Observed susceptibility is related to intrinsic susceptibility by:

$$
1 / k_{o}=1 / k_{i}+N=H_{c} / \text { const }+N
$$

This is the basis for the plot shown in Figure 6. The reduction in observed susceptibility after deformation (Figure 4) can be attributed to either reduced intrinsic susceptibility due to increased defect density impeding domain wall translation and rotation of the magnetization within domains, or increased demagnetizing factor $N$, or both. On the plot of $1 / k_{o}$ versus $H_{C} / M_{s}$ (Figure 6), there is a strong cluster of data points containing the weakly deformed and undeformed samples. More strongly deformed samples generally plot higher and/or to the right of this cluster. The samples that plot directly above the cluster (samples 4 and 5) have lower mean normalized susceptibility than undeformed samples, but similar coercivity, suggesting that $k_{i}$ has not changed (equation 3) but $N$ has increased (equation 4). Conversely, samples far to the right (e.g., 2 and 23) have increased $H_{c}$, implying reduced $k_{i}$. Baleyev and Absalyamov [1983] also found an irreversible decrease of approximately $10 \%$ in $k_{o}$ in $35-75 \mu \mathrm{m}$ magnetites after application of $120 \mathrm{MPa}$ quasihydrostatic stress. Their measured defect densities showed strong increases, suggesting that the reduction in $k_{o}$ was primarily due to decreased $k_{i}$.

For high intrinsic susceptibility, $1 / k_{o}$ is approximately equal to the average demagnetizing factor $N$. The intrinsic susceptibility of magnetite is on the order of $50 \mathrm{SI}$, and the approximation should be very good [e.g., Stacey and Banerjee, 1974]. Thus the question arises: can the observed $10 \%$ reduction in $k_{o}$ be accounted for by a decrease in $k_{i}$ ? A $50 \%$ increase in $H_{c}$ for the most strongly deformed samples (Figure 5) implies a reduction of $k_{i}$ by $1 / 3$ (equation 3). Taking 0.2 (the intercept of the best fit line in Figure 6 ) as the mean value for $N$, and 50 SI for intrinsic susceptibility before deformation gives, by (4), $1 / k_{o}=0.22$. The same value of $N$ and an intrinsic susceptibility reduced by deformation to $2 / 3$ $\left(k_{i}=33\right)$ predicts $1 / k_{o}=0.23$, less than a $5 \%$ change in observed susceptibility. In order to attain a $10 \%$ decrease in observed susceptibility with a constant value of $N \sim 0.2$, either the intrinsic susceptibility must decrease by more than a factor $H_{c o} / H_{\mathrm{cd}}$ (in violation of equation 3 ), or the initial value of $k_{i}$ must be lower than 50 SI. If the magnetites we have used were "prestressed," they may have had low $k_{i}$, but in order to satisfy equations 3 and 4 with a constant value of $N \sim 0.2$ and the measured values of $k_{o}$ before and after deformation, we require very low starting values of $k_{i}$, in the neighborhood of $10 \mathrm{SI}$. Thus it seems that $N$ may have changed during deformation, as well as $k_{i}$. Since $N \gg 1 / k_{i}$, a $10 \%$ increase in $N$ should result in about a $10 \%$ decrease in $k_{0}$.

Until recently, the average value of $N$ for any multidomain ferrimagnetic particle was considered to be constant $(1 / 3$ in SI units). However, Merrill [1977] showed that $N$ is dependent upon the internal domain configuration. Dunlop [1983] has calculated that $N$ varies with grain size, from a minimum of 0.13 for twodomain (2D) particles, up to $1 / 3$ for large MD grains. It is possible that the samples lying above the undeformed cluster in Figure 6 (samples 4 and 5) happen to have a different mean grain size due to heterogeneity of the magnetite powder and imperfect mixing. Dunlop [1983] calculates that $N$ also increases with displacement of domain walls from their minimum energy position, by as much as $40 \%$ for saturated $2 \mathrm{D}$ grains. It is conceivable that stresses may move and pin domain walls with displacement sufficient to increase $N$ at least by a few percent, and thus help to decrease $k_{o}$. 
In contrast to the changes in mean susceptibility and coercivity, which were relatively small for applied differential stresses less than about 100 or $150 \mathrm{MPa}$, mean ARM increased significantly even after application of hydrostatic stress. However it is important to point out that the stresses experienced by the magnetite particles were not hydrostatic, especially while shortening strains were less than about $15 \%$ and porosity was significant. Under those circumstances, the stresses applied at the specimen boundaries are transmitted to the interior particles across discrete grain contacts. This has two important consequences. First, even though the externally applied stress was hydrostatic, the stress field experienced by individual magnetite particles must have been more complex, determined by the contact geometry with other particles. Second, the stresses at the grain level were higher, and perhaps much higher, than those applied externally, because the grain contact areas are much smaller than the sample's external surface area. Zhang et al. [1990] for example, have recently studied crushing of quartz grains in porous sandstones subjected to only moderate applied hydrostatic stresses.

The increase in mean $k_{a}$ after application of a hydrostatic external stress, therefore, is probably due to highly localized development of deformation microstructures near grain contacts, where stresses are largest and most heterogeneous. It is not surprising that increased anhysteretic susceptibility is the first effect observed in these samples, because the other properties we have considered, low-field susceptibility and high-field hysteresis, are essentially "whole grain" phenomena, whereas ARM in coarse magnetites is often considered to reside in localized "pinning sites," where high defect concentrations or high stresses provide stability. This may also account for the apparent lack of stress sensitivity of ARM memory after LTD: if the ARM resides primarily in localized "hardened" areas, even in the samples which were only stressed hydrostatically, then there is no strong reason for the ARM stability to increase with externally applied stress. However, the total volume of such "hardened" areas increases with higher applied stresses, and therefore the anhysteretic susceptibilities increase as well.

Shive [1969] showed that experimental TRM intensities in nickel monocrystal samples were proportional to defect density, in contrast to the $n^{1 / 2}$ dependence of $M_{r s}$ and $H_{c}$. Our data appear to indicate that the ARM intensities in MD magnetite depend much less strongly on defect density. The $50 \%$ increase in $H_{c}$ implies roughly a factor of two increase in defect density in the magnetites of the most strongly deformed samples $\left(1.5 \sim H_{c d} / H_{c O}=\left[n_{d} / n_{0}\right]^{1 / 2}\right)$. However the maximum increase in anhysteretic susceptibility is only $25 \%$ to $30 \%$, indicating approximately an $n 1 / 3$ or $n^{1 / 4}$ dependence for $k_{\mathrm{a}}$ $\left(k_{a d} / k_{a 0} \sim 1.25=\left[n_{d} / n_{0}\right]^{1 / 4}\right) . \quad$ ARM theory [Jaep, 1971; Gillingham and Stacey, 1971], summarized by Dankers [1978] predicts

$$
k_{a}=M_{r s} / H_{c r}
$$

This is in broad agreement with an $n 1 / 4$ dependence for $k_{a}$, since $M_{r s}$ is closely proportional to $H_{c}$ and thus to $n^{1 / 2}$ (Figure 5), while $H_{c r}$ changes more slowly as a function of stress and of defect density.

The progressive, irreversible changes we have documented in rock magnetic properties as a function of applied stress are qualitatively compatible with previous observations of enhanced magnetic "hardness" in crushed and seived magnetites, in comparison to unstressed or annealed particles of similar size [e.g., Lowrie and Fuller, 1969; Heider et al., 1987]. However, relatively few previous experimental studies have quantified progressive irreversible changes in these properties with increasing applied stress or deformation [Carmichael, 1968b; Shive, 1969; Baleyev and Absalyamov, 1983]. Therefore we have reexamined unpublished data obtained in four sets of earlier experiments, involving deformation by pure shear and by simple shear, and with sand-sized calcite or quartz in the matrix [Borradaile and Alford, 1987, 1988]. All of these previous experiments used natural magnetite, coarser than that used in the present study. A decrease of $k_{\text {mean }}$ with strain occurred in one set of experiments, using pure shear and quartz sand (Figure 18). No significant changes in mean susceptibility were produced by experimental deformation of quartz sandstones by simple shear, or of calcite sandstones by either pure or simple shear.

The different strain sensitivities of $k_{\text {mean }}$ in different materials and under different conditions of deformation can be readily explained, at least in a qualitative sense. The difference between the results obtained using silicate sand ( $k_{\text {mean }}$ decreasing with pure shear strain) and calcite sand ( $k_{\text {mean }}$ constant) is undoubtedly related to the greater ductility of calcite. The magnetite particles experience larger differential stresses in a silicate matrix, and thus whatever the mechanism of the "magnetic hardening" may be, it is driven more efficiently in the quartz samples. Similarly, the difference between pure and simple shear results may be qualitatively explained in terms of the larger differential stresses applied in the former.

It is more difficult to explain the difference between the previous pure-shear calcite-matrix experiments, where no change in $k_{\text {mean }}$ was observed, and the present set. The principal difference in the two sets of experiments is the nature of the magnetite; Borradaile and Alford [1987, 1988] used natural magnetite with a mean grain diameter of approximately $200 \mu \mathrm{m}$, whereas in this study we have used a commercially obtained magnetite powder with a mean particle diameter of $40 \mu \mathrm{m}$. It seems unlikely that the magnetite grains of this study experienced substantially higher stress levels during laboratory deformation than those of the previous experiments. However, it is conceivable that the magnetite used in the previous experiments had even higher initial internal stress levels (as a result of prior history) and was thus "prehardened," as discussed above, with high defect concentrations substantially unaffected by the deformation experiments. Alternatively, it is plausible that the finer-grained magnetite used in the present study lost a fraction of its measured susceptibility because of an increase in demagnetizing factor rather than a reduction of intrinsic susceptibility.

\section{Changes in Remanence}

The changes in orientation and intensity of remanence are probably due to a combination of stress and strain effects. The low-coercivity overprint is present, but small, even in the samples to which only a hydrostatic stress was applied. The intensity of the overprint is much larger in samples subjected to higher differential stresses (Figure 9), but it is confined to the same range of relatively low coercivities (up to about $\mathbf{2 0} \mathrm{mT}$ ). This behavior is essentially identical to that described by Lanham and Fuller [1988], which they attributed to unblocking of "soft" domain walls by stress, enabling the walls to respond to weak ambient fields.

The reorientation of the stable ARM appears to be controlled primarily by particle rotation associated with bulk strain rather than by applied stress (Figure 10 and Table 3). This is compatible with the idea discussed above, that ARM resides primarily in localized areas of high stress and/or high defect concentration. Such areas 

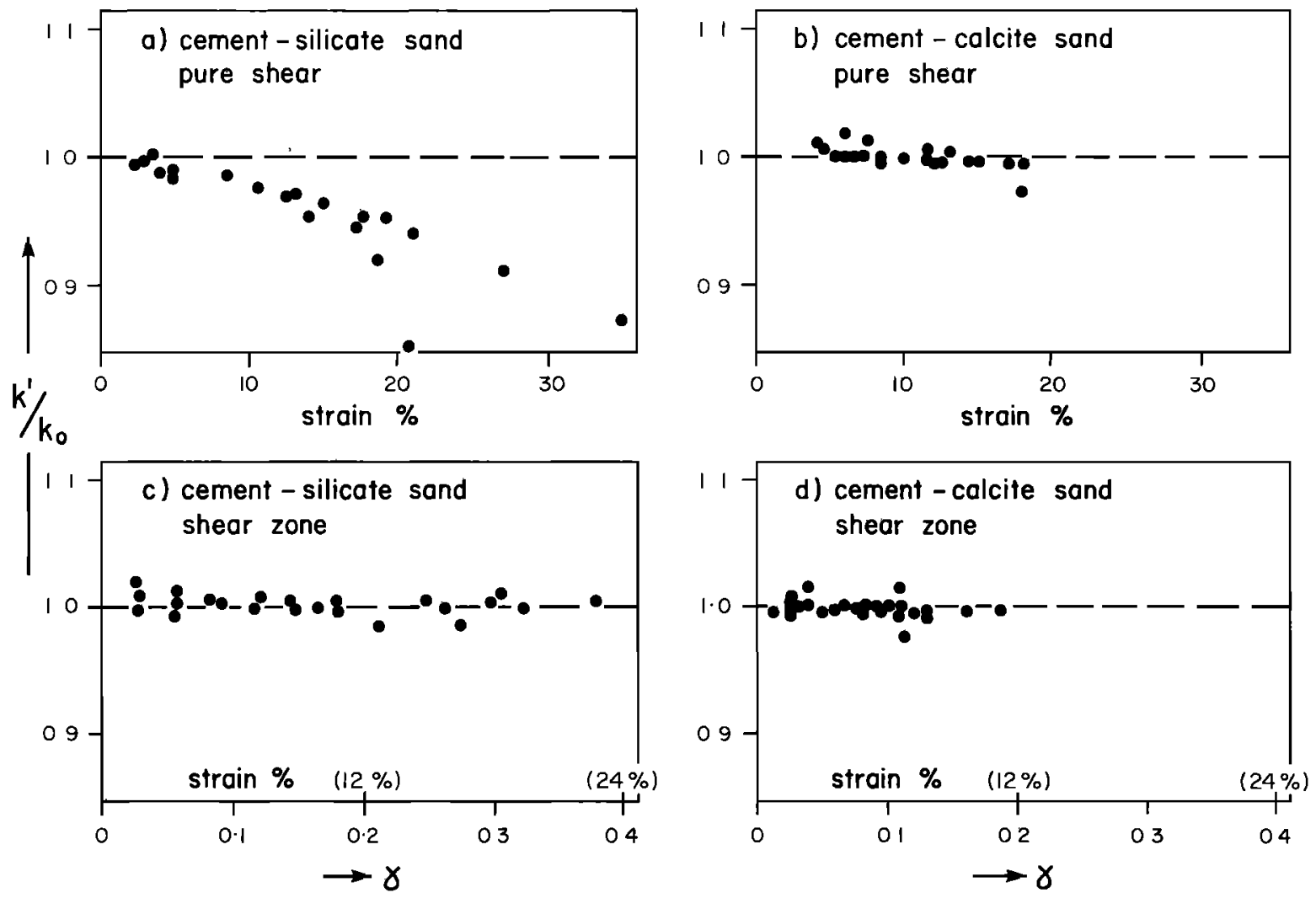

Fig. 18. Changes in $k$ mean with deformation for different styles of deformation and different matrix compositions (unpublished data from earlier experiments of G. J. Borradaile and C. Alford).

produced during initial sizing of the magnetites acquire the ARM before deformation and hold it as the particles reorient by particulate flow. The observed strain dependence, with little change in inclination up to $10 \%$ shortening, and rapid rotation thereafter (Figures 10 and 11), reflects the change in mechanism of strain accomodation inferred from Figure $2 b$. Initial shortening is taken up by reduction of porosity with little fabric development (Figure 3). After about $10 \%$ shortening and $10 \%$ volume loss, the matrix grains are in sufficient contact to transmit the applied stresses through the volume of the sample, and fabric development begins as the particles reorient in response to the stress.

However, the fact that some samples exhibit a steeper postdeformational remanence is difficult to explain without calling upon preferential demagnetization of the horizontal component, presumably by stress. An additional observation to be made from Figure $2 b$ is that $10 \%$ strain roughly corresponds in these samples to a maximum applied differential stress of $50 \mathrm{MPa}$ (500 bars). This coincides closely with the differential stress required to override the magnetocrystalline anisotropy of magnetite, according to the theoretical and experimental work of Carmichael [1968b] (Syono [1965] estimates $75 \mathrm{MPa}$ ). Much lower stresses (5 MPa) can trigger domain wall nucleation [Boyd et al., 1984], but there is little evidence for any effects of such low stresses on the magnetic properties of these samples. The sudden onset of changes in remanence orientation and intensity at about $50 \mathrm{MPa}$ may indicate magnetocrystalline control of part of the ARM. This relatively soft part of the ARM would be more easily removed by stress during deformation, as well as during low-temperature demagnetization. Preferential removal of such a soft ARM fraction could account for steepening of the remanence, if the harder fraction has a steeper orientation [Borradaile and Mothersill, 1989, 1991; Borradaile, 1992]. As noted previously, the predeformational maximum $\left[\mathrm{k}_{\mathrm{a}}\right]$ axes were steeply inclined for the samples with steepened postdeformational remanence.

\section{Changes in Magnetic Anisotropy}

It is clear from Figures 14 through 17 that susceptibility anisotropy changes very systematically as a function of bulk shortening, whereas ARM anisotropy changes more systematically as a function of peak applied stress. This implies that AMS arises primarily by reorientation of magnetite particles, while ARM anisotropy develops by the production of localized anisotropic regions within magnetite grains near their points of contact with other grains, where stresses are highest.

The changes in AMS with strain show some interesting similarities to, as well as differences from, the results of the the most directly relevant previous study, that of Borradaile and Alford [1987]. There it was reported that the change in the anisotropy ratio $\left(\Delta P^{\prime}=P^{\prime}{ }_{d}-P_{o}^{\prime}{ }_{o} ;\right.$ for values near $1, P^{\prime} \sim P=\max / \mathrm{min}$ [Jelinek, 1981]) was essentially linearly related to the strain ratio $X / Z$. The slope of this linear relationship was very close to unity, suggesting that the deformation of the magnetic ellipsoids was almost precisely the same as that of the material, as in this study (after allowing for the "threshhold strain"). It can also be seen on the plot of $\Delta P^{\prime}$ versus $X / Z$ of Borradaile and Alford [1987] that the linear trend defined by the data does not pass through the origin, but intersects the strain axis at about $3 \%$ strain. Thus the $10 \%$ strain threshhold that is such a prominent feature in the results of this study is absent in the earlier results; this is probably related to the much larger grain size of the magnetite used in the previous study. The magnetite particles used in this study are significantly smaller than the calcite framework grains, which may have shielded them during the initial stages of deformation. 
Our results also echo those of Borradaile and Alford [1987] in showing that bulk strain, involving particle reorientation, rather than microstrain or stress, controls the development of AMS. They reported that "wet" specimens showed anisotropy changes that were comparable to those of the "dry" samples, as is the case for AMS in this study.

ARM anisotropy, in contrast, appears to be more strongly controlled by stress. If, as we have discussed above, ARM resides primarily in localized regions of high defect concentration within grains, we can interpret the development of ARM anisotropy in the following way. ARM initially resides in areas stressed during preparation of the magnetite powders. Anhysteretic susceptibility is essentially isotropic because the magnetite grains, and these stressed areas within them, are randomly oriented. On application of a hydrostatic external stress, deformation microstructures are generated by stresses at grain-grain contacts, and mean anhysteretic susceptibility increases, but it is still essentially isotropic because the contacts and associated stresses are not systematically oriented. On application of moderate external differential stresses, porosity reduction and fabric development begin. After about $10 \%$ shortening, a load-supporting framework of grains has developed, and the stresses associated with vertical grain-grain contacts become larger than those associated with horizontal contacts. An anisotropic distribution of dislocations is thereby generated, resulting in horizontal maximum anhysteretic susceptibility.

\section{Implications of Experimental Results to Naturally Deformed Rocks}

In these experiments we have simulated the processes that occur in natural deformation of magnetite-bearing granular rocks of low to moderate porosity. The dominant mechanism of strain was disordered grain-scale translation, or particulate flow. Both flow associated with bulk strain and anelastic response of magnetite particles to stresses transmitted by neighboring grains played important roles in changing the magnetic properties. Obviously, there are many naturally deformed rocks to which these results are not applicable. The dominant mechanisms of natural deformation in many settings involve dissolution and removal or recrystallization of material [e.g., Marshak and Engelder, 1985; Meike and Wenk, 1988; Drury and Urai, 1990], in contrast to the constantvolume (after porosity closure) deformation that we have simulated. Many studies of the effects of strain on anisotropy and on remanence have focussed on hematite-bearing rather than magnetite-bearing rocks. It is important to recognize that magnetic mineralogy and strain mechanisms play critical roles in determining the effects of deformation on the magnetic properties of rocks. The conclusions we draw from these experiments should therefore be applied only to rocks with similar magnetic carriers, deformed by similar mechanisms in nature.

An important implication of these results is that initially homogeneous rocks with uniform susceptibility may, during natural deformation, develop susceptibility gradients that are inversely related to strain gradients. Such a situation, for example, has been described by Goldstein and Brown [1988], in a study of mylonitic rocks from the Brevard zone. Mean susceptibility was observed to decrease substantially toward the center of the mylonite zone; Goldstein and Brown explained this in terms of comminution of magnetites during mylonitization.

Unfortunately, the decrease we have observed in mean susceptibility with deformation complicates the method suggested by Henry [1983] and Henry and Daly [1983] for analysis of AMS data, wherein the variation in anisotropy as a function of mean susceptibility is used to determine the separate ferromagnetic and paramagnetic susceptibility tensors for a set of samples. The method is based on the premise that for rocks that have undergone reasonably homogeneous deformation, the relative content of ferromagnetic trace minerals is likely to be more variable than the major mineral content or the intensity of the bulk rock fabric. Thus the paramagnetic susceptibility tensor is considered invariant over the sample set, and changes in mean susceptibility and in anisotropy are both directly related to ferromagnetic content. If, for example, anisotropy is observed to decrease with increasing mean susceptibility, this method of analysis would lead to the interpretation that the anisotropy derives primarily from paramagnetic matrix material, and that the ferromagnetic material is relatively isotropic or even possesses an inverse anisotropy. However, the results of this study show that such a dependence of anisotropy upon mean susceptibility may have a very different explanation. The more strongly deformed samples here show both increased anisotropy and decreased $k_{\text {mean }}$ relative to the weakly deformed samples; this closely matches the hypothetical pattern described above. It is clear that application of Henry's method to this set of samples would lead to an entirely erroneous interpretation. Thus it is important to exercise due caution in the application of this method.

\section{SUMMARY AND CONCLUSIONS}

We have found that experimental deformation of synthetic sandstone analogs containing $40 \mu \mathrm{m}$ magnetite produces significant changes in orientation of anhysteretic remanence, in bulk magnetic properties, and in magnetic anisotropy. All of these changes proceed slowly for shortening strains below about $10 \%$ and much more rapidly at higher strains. Samples deformed with a pore fluid present experienced lower differential stresses, and their coercivity, saturation remanence, and ARM anisotropies did not increase as much as those deformed dry; however, their remanence orientation and their AMS showed changes comparable to those of the samples deformed without pore fluid present. The former properties thus were controlled primarily by stress, whereas the latter were more strongly controlled by bulk strain.

For samples deformed up to about $10 \%$, the remanence is reoriented much more slowly with strain than a "nonmaterial line," the mean susceptibility is not significantly decreased, the mean ARM is increased by about $10 \%$, and the ARM and AMS ellipsoids are only slightly "deformed." For samples strained beyond $10 \%$, remanence orientation changes much faster than a "nonmaterial line," ARM increases and susceptibility decreases rapidly with increasing deformation, and the AMS ellipsoids behave more or less as "passive markers," deforming at the same rate as the samples themselves.

Acknowledgments. This study was funded by NSF EAR $88-04820$ and NSERC A6861. We thank Bruce Moskowitz for various discussions and a critical reading of the manuscript. Mark Hudson and an anonymous referee provided helpful and thorough reviews. This is IRM contribution 9108.

\section{REFERENCES}

Amin, N., S. Arajs, and E. Matijevic, Magnetic properties of uniform spherical magnetite particles prepared from ferrous hydroxide gels, Phys. Status Solidi A, 101, 233-238, 1987.

Appel, E., Stress anisotropy in Ti-rich titanomagnetites, Phys. Earth Planet. Int., 46, 233-240, 1987.

Baleyev, K. A., and S. S. Absalyamov, Investigation of the dislocation structure and magnetic properties of magnetite crystals in conditions of high mechanical stress, Izv., Earth Phys., 19, 618-624, 1983.

Banerjee, S. K., J. King, and J. Marvin, A rapid method for magnetic granulometry with applications to environmental studies, Geophys. Res. Lett., 8, 333-336, 1981. 
Borradaile, G. J., Particulate flow of rock and the formation of cleavage, Tectonophysics, 72, 305-321, 1981.

Borradaile, G. J., Anisotropy of magnetic susceptibility: rock composition versus strain, Tectonophysics, 138, 327-329, 1987.

Borradaile, G. J., Magnetic susceptibility, petrofabrics and strain - a review, Tectonophysics, 156, 1-20, 1988.

Borradaile, G. J., Correlation of strain with anisotropy of magnetic susceptibility (AMS), Pure Appl. Geophys., 135, 15-29, 1991.

Borradaile, G. J., Experimental deformation of two-component IRM in magnetite-bearing limestone: $A$ model for the behavior of NRM during natural deformation, Phys. Earth Planet. Int., 70, 6477, 1992.

Borradaile, G. J., and C. Alford, Relation between magnetic susceptibility and strain in laboratory experiments, Tectonophysics, 133, 121-135, 1987.

Borradaile, G. J., and C. Alford, Experimental shear zones and magnetic fabrics, J. Struct. Geol., 10, 895-904, 1988.

Borradaile, G. J., and J. Mothersill, Tectonic strain and paleomagnetism: experimental investigation, Phys. Earth Planet. Inter., 56, 254-265, 1989.

Borradaile, G. J., and J. Mothersill, Experimental strain of isothermal remanent magnetization in ductile sandstone, Phys. Earth Planet. Inter., 65, 308-318, 1991.

Borradaile, G. J., and D. Tarling, The influence of deformation mechanisms on magnetic fabrics in weakly deformed rocks, Tectonophysics, 77, 151168,1981 .

Borradaile, G. J., and D. H. Tarling, Strain partitioning and magnetic fabrics in particulate flow, Can. J. Earth Sci., 21, 694-697, 1984.

Boyd, J. R., M. Fuller, and S. Halgedahl, Domain wall nucleation as a controlling factor in the behavior of fine magnetic particles in rocks, Geophys. Res. Lett., 11, 193-196, 1984.

Carmichael, R. S., Remanent and transitory effects of elastic deformation of magnetic crystals, Philos. Mag., 17, 911-927, 1968a.

Carmichael, R. S., Stress control of magnetization in magnetite and nickel, and implications for rock magnetism, J. Geomagn. Geoelectr., 20, 187$196,1968 b$.

Cogné, J. P., and D. Gapais, Passive rotation of hematite during deformation: a comparison of simulated and natural redbed fabrics, Tectonophysics, 121, 365-372, 1986.

Cogné, J. P., and H. Perroud, Strain removal applied to paleomagnetic direction in an orogenic belt: the Permian red slates of the Alpes Maritimes, France, Earth Planet. Sci. Lett., 72, 125-140, 1985.

Cogné, J. P., and H. Perroud, Unstraining paleomagnetic vectors: the currrent state of debate, Eas Trans. AGU, 68, 705-712, 1987.

Cogné, J.-P., and H. Perroud, Anisotropy of magnetic susceptibility as a strain gauge in the Flamanville granite, NW France, Phys. Earth Planet. Inter., 51, 264-270, 1988.

Cogné, J. P., H. Perroud, M. P. Trexier, and N. Bonhommet, Strain reorientation of hematite and its bearing upon remanent magnetization, Tectonics, 5, 753-767, 1986.

Dankers, P., Magnetic properties of dispersed natural iron-oxides of known grain-size, Ph.D. thesis, Univ. of Utrecht, Utrecht, 1978.

Donath, F. A., Rock deformation apparatus and experiments for dynamic structural geology, J. Geol. Educ., 18, 3-12, 1970.

Drury, M. and J. L. Urai, Deformation-related recrystallization processes, Tectonophysics, 172, 235-253, 1990.

Dunlop, D. J., On the demagnetizing energy and demagnetizing factor of a multidomain ferromagnetic cube, Geophys. Res. Lett., 10, 79-82, 1983.

Dunlop, D. J., and K. S. Argyle, Thermoremanence and anhysteretic remanence of small multidomain magnetites, J. Geophys. Res., 95, 4561$4577,1990$.

Dunlop, D. J., Ö. Özdemir, and R. J. Enkin, Multidomain and single-domain relations between susceptibility and coercive force, Phys. Earth Planet. Int., 49, 181-191, 1987.

Facer, R. A., Folding, strain, and Graham's fold test in paleomagnetic investigations, Geophys. J. R. Astr. Soc., 72, 165-171, 1983.

Gillingham, D. E. W. and F. D. Stacey, Anhysteretic remanent magnetization (ARM) in magnetite grains, Pure Appl. Geophys., 8, 160$165,1971$.

Girdler, R. W., The measurement and computation of anisotropy of magnetic susceptibility in rocks: Geophys. J. R. Astron. Soc., 5, 34-44, 1961.

Goldstein, A., and L. Brown, Magnetic susceptibility anisotropy of mylonites from the Brevard Zone, North Carolina, USA, Phys. Earth Planet. Int., 51, 290-390, 1988.

Graham, J. W., Significance of magnetic anisotropy in Appalachian sedimentary rocks, in The Earth Beneath the Continents, Geophys. Monogr. Ser., vol. 10, edited by J. S. Steinhart and T. J Smith, pp. 627 648, AGU, Washington DC, 1967.
Graham, J. W., A. F. Buddington, and J. R. Balsley, Stress-induced magnetization of some rocks with analyzed magnetic minerals, $J$. Geophys. Res., 62, 465-474, 1957.

Halgedahl, S., Domain pattern observations in rock magnetism: progress and problems, Phys. Earth Planet. Inter., 46, 127-163, 1987.

Heider, F., D. J. Dunlop, and N. Sugiura, Magnetic properties of hydrothermally recrystallized magnetite crystals, Science, 236, 1287-1290, 1987.

Heider, F., H. C. Soffel, and D. J. Dunlop, Low-temperature demagnetization (LTD) of SIRM and TRM in magnetite grains $(0.037 \mu \mathrm{m}$ to $4 \mathrm{~mm}$ ), abstract, Eos Trans. AGU, 71, 1287, 1990.

Hennig-Michaeli, C., and H. Siemes, Zwillungsgleitung beim Magnetite, Neues Jahrb. Mineral. Abh., 123, 330-334, 1975.

Henry, B., Interprétation quantitative de l'anisotropie de susceptibilité magnetique, Tectonophysics, 91, 165-177, 1983.

Henry, B., and L. Daly, From qualitative to quantitative magnetic anisotropy analysis: The prospect of finite strain calibration, Tectonophysics, 98, 327-336, 1983.

Henry, B., and F. Hrouda, Analyse de la déformation finie des roches par détermination de leur anisotropie de susceptibilité magnétique, $C$. $R$. Acad. Sci. Ser. 2, 308, 731-737, 1989.

Hirt, A., W. Lowrie, and O. A. Pfiffner, A paleomagnetic study of tectonically deformed red beds of the Glarus nappe complex, eastern Switzerland, Tectonics, 5, 723-731, 1986.

Hirt, A., W. Lowrie, W. Clendenen, and R. Kligfield, The correlation of magnetic anisotropy with strain in the Chelmsford formation of the Sudbury Basin, Ontario, Tectonophysics, 145, 177-189, 1988.

Hodych, J. P., Magnetostrictive control of coercive force in multidomain magnetite, Nature, 298, 542-544, 1982.

Hodych, J. P., Evidence for magnetostrictive control of intrinsic susceptibility and coercive force of multidomain magnetite in rocks, Phys. Earth Planet. Inter., 42, 184-194, 1986.

Hrouda, F., A model for the orientation process of ferromagnetic minerals in slates, Earth Planet. Sci. Lett., 33, 107-110, 1976.

Hrouda, F., Mathematical model relationship between the paramagnetic anisotropy and strain in slates, Tectonophysics, 142, 323-327, 1987.

Hrouda, F., Separation of tectonic deformation component from a complex magnetic fabric, J. Struct. Geol., in press, 1992.

Hudson, M. R., R. L. Reynolds, and N. S. Fishman, Synfolding magnetization in the Jurassic Preuss sandstone, Wyoming-Idaho-Utah thrust belt, J. Geophys. Res., 94, 13681-13705, 1989.

Jaep, W. F., Role of interactions in magnetic tapes, J. Appl. Phys., 42, 27902794, 1971

Jeffrey, G. B., The motion of ellipsoidal particles immersed in a viscous fluid, Proc. R. Soc. London, Ser. A, 102, 161-179, 1922.

Jelinek, V., Characterization of the magnetic fabrics of rocks, Tectonophysics, 79, T63-T67, 1981.

Kapicka, A., Anisotropy of magnetic susceptibility in a weak field induced by stress, Phys. Earth Planet. Inter., 51, 349-354, 1988.

Kean, W. F., R. Day, M. Fuller, and V. A. Schmidt, The effect of uniaxial compression on the initial susceptibility of rocks as a function of grain size and composition of their constituent titanomagnetites, J. Geophys. Res., 81, 861-872, 1976.

Kern, J. W., Effect of stress on the susceptibility and magnetization of a partially magnetized multidomain system, J. Geophys. Res., 66, 38073816, 1961a.

Kern, J. W., Stress stability of remanent magnetization, J. Geophys. Res., 66, 3817-3820, $1961 b$.

King, J., S. K. Banerjee, J. Marvin, and O. Ozdemir, A comparison of different magnetic methods for determining the relative grain size of magnetite in natural materials: some results from lake sediments, Earth Planet. Sci. Lett., 59, 404-419, 1982.

Kinoshita, H., Studies on piezomagnetization III - PRM and related phenomena, J. Geomagn. Geoelectr., 20, 155-167, 1968.

Kirschvink, J. L., The least-sqares line and plane and the analysis of paleomagnetic data, Geophys. J. R. Astron. Soc., 62, 699-718, 1980.

Kligfield, R., W. Lowrie, and I. W. D. Dalziel, Magnetic susceptibility as a strain indicator in the Sudbury Basin, Ontario: Tectonophysics, 40, 287308, 1977.

Kligfield, R., W. H. Owens, and W. Lowrie, Magnetic susceptibility, strain, and progressive deformation in Permian sediments from the Maritime Alps (France): Earth Planet. Sci. Lett., 55, 181-189, 1981.

Kligfield, R., W. Lowrie, and O. A. Pfiffner, Magnetic properties of deformed oolitic limestones from the Swiss Alps: the correlation of magnetic anisotropy and strain: Eclogae Geol. Helv., 75, 127-157, 1982.

Kligfield, R., W. Lowrie, A. Hirt, and A. W. B. Siddans, Effect of 
progressive deformation on remanent magnetization of Permian redbeds from the Alpes Maritimes (France), Tectonophysics, 97, 59-85, 1983.

Kneen, S. J., The relationship between the magnetic and strain fabrics of some hematite-bearing Welsh slates, Earth Planet. Sci. Lett., 31, 413-416, 1976.

Kobayashi, K., and M. Fuller, Stable remanence and memory of multidomain materials with special reference to magnetite, Philos. Mag. 18, 601-624, 1968.

Kodama, K., Remanence rotation due to rock strain during folding and the stepwise application of the fold test, J. Geophys. Res., 93, 3357-3371, 1988.

Kodama, K. P., and A. Cox, The effects of a constant volume deformation on the magnetization of an artificial sediment, Earth Planet. Sci. Lett., 38 , 436-442, 1978.

Lanham, M., and M. Fuller, Weak field control of remanent magnetization changes produced by uniaxial stress cycling, Geophys. Res. Lett., 15, 511$513,1988$.

Lowrie, W., and M. Fuller, Effect of annealing on coercive force and remanent magnetizations in magnetite, J. Geophys. Res., 74, 2698-2709, 1969.

Lowrie, W., A. M. Hirt, and R. Kligfield, Effects of tectonic deformation on the remanent magnetization of rocks, Tectonics, 5, 713-722, 1986.

March, A., Mathematische Theorie der Regelung nach der Korngestalt bei Affiner Deformation, Z. Kristallogr., 81, 285-297, 1932.

Marshak, S. and T. Engelder, Development of cleavage in limestones of a fold-thrust belt in eastern New York, J. Struct. Geol., 7, 345-359, 1985.

Martin, R. J. III, and J. S. Noel, The influence of stress path on thermoremanent magnetization, Geophys. Res. Lett., 15, 507-510, 1988.

Martin, R. J. III, R. E. Haberman, and M. Wyss, The effect of stress cycling and inelastic volume strain on remanent magnetization, J. Geophys. Res., 83, 3485-3496, 1978.

McCabe, C., M. Jackson, and B. B. Ellwood, Magnetic anisotropy in the Trenton limestone: results of a new technique, anisotropy of anhysteretic susceptibility, Geophys. Res. Lett., 12, 333-336, 1985.

Meike, A., and H.-R. Wenk, A TEM study of microstructures associated with solution cleavage in limestone, Tectonophysics, 154, 137-148, 1988.

Merrill, R.T., The demagnetizing field of multidomain magnetite, $J$. Geomagn. Geoelectr., 29, 285-292, 1977.

Morash, A., and N. Bonhommet, Deviation of IRM during simple shortening experiments (abstr), 4th Intl. Assoc. of Geomagn. and Aeron. Sci. Assem. Edinburgh, I13.12, 252, 1981.

Moskowitz, B. M., S. L. Halgedahl, and C. A. Lawson, Magnetic domains on unpolished and polished surfaces of $\mathrm{Ti}$ rich titanomagnetite, $J$. Geophys. Res., 93, 3372-3386, 1988.

Muller, P., and H. Siemes, Zur Festigkeit und Gefugeregulung von experimentell verformten Magnetiterzen, Neues Jahrb. Mineral. Abh., 117, 39-60, 1972.

Nagata, T., Basic magnetic properties of rocks under the effect of mechanical stresses, Tectonophysics, 9, 167-195, 1970.

Nagata, T., and B. J. Carleton, Notes on PRM of igneous rocks, $J$. Geomagn. Geoelectr., 20, 115-127, 1968.

Noltimier, H. C., Determining magnetic anisotropy of rocks with a spinner magnetometer giving in-phase and quadrature data output, $J$. Geophys. Res., 76, 4849-4854, 1971.

Ohnaka, M., Stability of remanent magnetization of rocks under compression - its relation to grain size of rock-forming ferromagnetic minerals, J. Geomagn. Geoelectr., 21, 495-505, 1969.

O'Reilly, W., Rock and Mineral Magnetism, 230 pp., Blackie, Glasgow, 1984.

Owens, W. H., Mathematical model studies on factors affecting the magnetic anisotropy of deformed rocks, Tectonophysics, 24, 115-131, 1974.

Owens, W. H., and E. H. Rutter, The development of magnetic susceptibility anisotropy through crystallographic preferred orientation in a calcite rock, Phys. Earth Planet. Inter., 16, 215-222, 1978.

Ozima, M., Effects of a plastic deformation on the remanent magnetization of a Cu-Co alloy, Earth Planet. Sci. Lett., 47, 121-123, 1980.

Park, J. K., E. I. Tanczyk, and A. Desbarats, Magnetic fabric and its significance in the $1400 \mathrm{Ma}$ Mealy diabase dykes of Labrador, Canada, $J$. Geophys. Res., 93, 13689-13704, 1988.

Rathore, J. S., Magnetic susceptibility anisotropy in the Cambrian slate belt of North Wales and correlation with strain, Tectonophysics, 53, 83-97, 1979.
Rathore, J. S., and B. Henry, Comparison of strain and magnetic fabrics in Dalradian rocks from the southwest Highlands of Scotland, J. Struct. Geol., 4, 373-384, 1982.

Revol, J., R. Day, and M. Fuller, Effect of uniaxial compressive stress upon remanent magnetization: stress cycling and domain state dependence, $J$. Geomagn. Geoelectr., 30, 593-599, 1977.

Rochette, P., Magnetic susceptibility of the rock matrix related to magnetic fabric studies, J. Struct. Geol., 9, 1015-1020, 1987.

Rochette, P., La susceptibilité anisotrope des roches faiblement magnétiques: Origines et applications, thesis, Univ. Joseph Fourier, Grenoble, France, 1988.

Ruf, A., S. Naruk, R. Butler, and G. Calderone, Strain and magnetic fabric in the Santa Catalina and Pinaleno Mountains metamorphic core complex mylonite zones, Arizona, Tectonics, 7, 235-248, 1988.

Rutter, E. H., The influence of temperature, strain rate, and interstitial water in the experimental deformation of calcite rocks, Tectonophysics, 22, 311334, 1974.

Rutter, E. H., B. K. Atkinson, and D. H. Mainprice, On the use of the stressrelaxation testing method in studies of the mechanical behavior of geological materials, Geophys. J. R. Astron. Soc., 55, 155-170, 1978.

Shive, P. N., The effect of internal stress on the thermoremanence of nickel, J. Geophys. Res., 74, 3781-3788, 1969.

Singh, J., D. J. Anderson, and D. H. Tarling, The magnetic susceptibility anisotropy of deformed rocks from North Cornwall, England, Tectonophysics, 27, 141-153, 1975.

Smith, B. E., and M. J. S. Johnston, A tectonomagnetic effect observed before a magnitude 5.2 earthquake near Hollister, California, J. Geophys. Res., 81, 3556-3560, 1976.

Soffel, H., Stress-dependence of the domain structure of natural magnetite, Z. Geophys., 32, 63-77, 1966.

Stacey, F. D., The physical theory of rock magnetism, Adv. Phys., 12, 45133, 1963.

Stacey, F. D., and S. K. Banerjee, Physical Principles of Rock Magnetism, Elsevier, Amsterdam, 1974

Stoner, E. C., and E. P. Wohlfarth, A mechanism of magnetic hysteresis in heterogeneous alloys, Philos. Trans. R. Soc. London, A240, 599-642, 1948.

Syono, Y., Magnetocrystalline anisotropy and magnetostriction of $\mathrm{Fe}_{3} \mathrm{O}_{4}$ $\mathrm{Fe}_{2} \mathrm{TiO}_{4}$ series, with special application to rock magnetism, Japan. J. Geophys., 4, 71-143, 1965.

van der Pluijm, B. A., Grain scale deformation and the fold test - evaluation of synfolding remagnetization, Geophys. Res. Lett., 14, 155-157, 1987.

Vetter Jr., J. R., K. P. Kodama, and A. Goldstein, Reorientation of remanent magnetization during tectonic fabric development: an example from the Waynesboro Formation, Pennsylvania, USA, Tectonophysics, 165, 29-40, 1989.

Wood, D. S., G. Oertel, J. Singh, and M. F. Bennett, Strain and anisotropy in rocks, Philos. Trans. $R$. Soc. London, Ser. A, 283, 27-42, 1976.

Worm, H.-U., P. J. Ryan, and S.K. Banerjee, Domain size, closure domains, and the importance of magnetostriction in magnetite, Earth Planet. Sci. Lett., 102, 71-78, 1991.

$\mathrm{Xu}, \mathrm{S}$., and D. J. Dunlop, Numerical modeling of microcoercivity and hysteresis parameters of multidomain samples, abstract, Eos Trans. AGU, 71, 1287, 1990.

$\mathrm{Xu}, \mathrm{S}$., and R. T. Merrill, Microstress and microcoercivity in multidomain grains, J. Geophys. Res., 94, 10627-10636, 1989.

Xu, S., and R. T. Merrill, Microcoercivity, bulk coercivity, and saturation remanence in multidomain materials, J. Geophys. Res., 95, 7083-7090, 1990.

Zhang, J., T.-F. Wong, and D. M. Davis, Micromechanics of pressureinduced grain crushing in porous rocks, J. Geophys. Res., 95, 341-352, 1990.

Zijderveld, J. D. A., A.C. demagnetization of rocks: Analysis of results, in Methods in Paleomagnetism, edited by D. W. Collinson et al., p. 254-286, Elsevier Amsterdam, 1967.

S. Banerjee, P. Hudleston, and M. Jackson, Department of Geology and Geophysics, University of Minnesota, Minneapolis, MN 55455.

G. Borradaile, Department of Geology, Lakehead University, Thunder Bay ON, Canada P7B 5E1.

(Received September 16, 1991; revised, March 12, 1992; accepted April 16, 1992.) 